\title{
Attributes of God: Conceptual Foundations of a Foundational Belief
}

\author{
Andrew Shtulman, ${ }^{\mathrm{a}}$ Marjaana Lindeman ${ }^{\mathrm{b}}$ \\ ${ }^{a}$ Department of Psychology, Occidental College \\ ${ }^{\mathrm{b}}$ Institute of Behavioural Sciences, University of Helsinki
}

Received 13 March 2014; received in revised form 11 November 2014; accepted 24 February 2015

\begin{abstract}
Anthropomorphism, or the attribution of human properties to nonhuman entities, is often posited as an explanation for the origin and nature of God concepts, but it remains unclear which human properties we tend to attribute to God and under what conditions. In three studies, participants decided whether two types of human properties - psychological (mind-dependent) properties and physiological (body-dependent) properties - could or could not be attributed to God. In Study 1 $(n=1,525)$, participants made significantly more psychological attributions than physiological attributions, and the frequency of those attributions was correlated both with participants' religiosity and with their attribution of abstract, theological properties. In Study $2(n=99)$ and Study $3(n=138)$, participants not only showed the same preference for psychological properties but were also significantly faster, more consistent, and more confident when attributing psychological properties to God than when attributing physiological properties. And when denying properties to God, they showed the reverse pattern - that is, they were slower, less consistent, and less confident when denying psychological properties than when denying physiological properties. These patterns were observed both in a predominantly Christian population (Study 2) and a predominantly Hindu population (Study 3). Overall, we argue that God is conceptualized not as a person in general but as an agent in particular, attributed a mind by default but attributed a body only upon further consideration.
\end{abstract}

Keywords: Religious cognition; Anthropomorphism; God concepts; Folk theories; Conceptual development

\section{Introduction}

The Greek philosopher Xenophanes of Colophon once noted, "If cattle or horses or lions had hands and could draw and could sculpt like men, then the horses would draw

Correspondence should be sent to Andrew Shtulman, Department of Psychology, Occidental College, Los Angeles, CA 90041. E-mail: shtulman@oxy.edu. 
their gods like horses, and the cattle like cattle; and each they would shape bodies of gods in the likeness, each kind, of their own" (Lesher, 1992). This intuition-that God concepts are essentially a projection of human properties onto a nonhuman entity-has remained popular for centuries. Many scholars have appealed to anthropomorphism as a way of explaining religion in general (Guthrie, 1993; Hume, 1757/2009; Tylor, 1871/ 1974) or God concepts in particular (Barrett \& Keil, 1996; Boyer, 2001; Kelemen, 2004). Guthrie (1993), for instance, has argued that belief in supernatural beings, including God, arises from an evolutionarily endowed propensity to interpret changes in the physical environment as products of intentional agency. Similarly, Boyer (2001) has argued that God concepts are highly memorable, and thus highly contagious, because they are built from one of our most inferentially rich and early developing ontologies: the "person" ontology.

Considering the sustained interest in anthropomorphism as an explanation for the origin and nature of God concepts, it is surprising how little we know about the human properties people actually attribute to God. Empirical research on God concepts has typically focused on the kinds of nonhuman properties people attribute to God, namely, immortality (Giménez-Dasí, Guerrero, \& Harris, 2005) and omniscience (Barrett, Richert, \& Driesenga, 2001; Knight, Sousa, Barrett, \& Atran, 2004; Lane, Wellman, \& Evans, 2010; Makris \& Pnevmatikos, 2007; Richert \& Barrett, 2005). While such properties surely constrain the scope of our inferences about God's actions, it is unclear whether they constitute the core of our God concepts or are merely an appendage onto an otherwise anthropomorphic concept. Other studies have, in fact, explored the types of human properties we attribute to God, but those studies have focused on whether God is conceptualized as an attachment figure and have therefore focused on attachment-related properties, like whether God is comforting, controlling, distant, or wrathful (Cassiba, Granqvist, Costantini, \& Gatto, 2008; De Roos, Miedema, \& Iedema, 2001; Dickie et al., 1997; Kirkpatrick, 2005). Although such studies shed light on the psychodynamic aspects of belief in God, they shed less light on the conceptual underpinnings of that belief.

In contrast to the dearth of research on the anthropomorphic underpinnings of belief in God, there is a wealth of research on the anthropomorphic underpinnings of everyday cognition. Psychological studies have shown that people regularly attribute human properties to nonhuman entities in an attempt to better understand them. Such entities include computers (Nass \& Moon, 2000), robots (Haslam, Kashima, Loughnan, Shi, \& Suitner, 2008), pets (Epley, Akalis, Waytz, \& Cacioppo, 2008), nature (White, 1992), science (Legare, Lane, \& Evans, 2013), animated shapes (Heider \& Simmel, 1944), and collections of moving objects (Bloom \& Veres, 1999). While a number of factors influence the strength and consistency of such attributions - for example, the applicability of intentional explanations to the phenomena at hand, the need to explain and predict those phenomena, the need to feel socially connected to others (Epley, Waytz, \& Cacioppo, 2007) - the basic tendency to attribute human properties to nonhuman entities appears to be automatic, widespread, and early-developing. Even infants adopt an "intentional stance" in the presence of self-moving objects, expecting such objects to move in a goal-directed manner (Gergely, Nadasdy, Csibra, \& Biro, 1995), exert stable preferences for some 
objects over others (Woodward, 1998), and interact contingently with other agents in the environment (Johnson, Slaughter, \& Carey, 1998).

One important caveat when applying these findings to theories of religious cognition is that the kind of anthropomorphism readily displayed from infancy to adulthood is not the attribution of all human properties to nonhuman entities but the attribution of basic psychological properties: beliefs, desires, intentions, emotions, and perceptions. This distinction is important for two reasons.

First, it has been suggested that God concepts are really just "person" concepts on to which God's extraordinary properties - omniscience, omnipotence, omnipresence-have been grafted (Boyer, 2001; see also Atran \& Norenzayan, 2004; Barrett, 2000). This stipulation is vital to the argument that religious concepts derive their memorability from inconsistencies between the concept's base ontology (in this case, "person") and its unique, nonnatural properties (in this case, properties like "never dies" and "is everywhere at once"). In other words, it is the inconsistency between (a) the belief that all people die and (b) the belief that God does not die, or (a) the belief that all people occupy one place at one time and (b) the belief God occupies all places at all times, that makes God concepts highly memorable and thus highly likely to be transmitted from one mind to another. On this view, God concepts are described as "minimally counterintuitive"less intuitive than ordinary (natural-kinds) concepts but more intuitive than concepts which violate several ontological commitments - and, as such, are conferred the memory advantages true of minimally counterintuitive concepts more generally (Banerjee, Haque, \& Spelke, 2013; Boyer \& Ramble, 2001; Johnson, Kelly, \& Bishop, 2010; Norenzayan, Atran, Faulkner, \& Schaller, 2006; Upal, Gonce, Tweney, \& Slone, 2007).

Second, it is commonly assumed that people have two distinct God concepts, a concrete anthropomorphic concept, held implicitly, and an abstract theological concept, held explicitly. The two God concepts are thought to be inconsistent with one another and to be used in different contexts (Atran \& Norenzayan, 2004; Bulbulia, 2004; Cohen, Shariff, \& Hill, 2008; Epley et al., 2007; Gray \& Wegner, 2010; Grysman \& Hudson, 2012; Pyysiäinen, 2004; Slone, 2004; Subbotsky, 2005). These conclusions are based on an influential study by Barrett and Keil (1996), in which participants' God concepts were assessed both directly, with specific questions about God's extraordinary properties, and indirectly, with a story-recall task. The authors found a discrepancy in participants' reasoning across the two tasks: While participants explicitly endorsed abstract, theological statements like "God knows everything" and "God can do multiple mental activities simultaneously," they nevertheless imposed human-like limitations on God's mental activities when recalling stories about God's actions (e.g., recalling a sentence like "God was aware of the girl's deed and was pleased by it" as "God was pleased by seeing the girl put the bird in its nest," which implies that God must perceive an event in order to become aware of it). This inconsistency has been taken to indicate that individuals hold two God concepts: a "theologically correct" concept, deployed when reasoning about God overtly and deliberately; and an anthropomorphic concept, deployed when reasoning about God covertly and spontaneously. Yet, without more detailed investigations of the kinds of human properties attributed to God and under what conditions, it remains unclear 
whether Barrett and Keil's (1996) findings are best interpreted as evidence of two globally distinct concepts or as evidence of a single concept plagued by local inconsistencies.

In light of the findings reviewed above, there are at least three ways people might anthropomorphize God. One way would be to conceptualize God as possessing a human mind but not a human body, that is, as a bodiless agent. This view is most consistent with the literature on everyday anthropomorphism, in which people have been observed to attribute human psychological properties to goal-directed objects (robots, animated shapes) and complex processes (nature, evolution) but have not been observed to attribute human physiological properties to those same entities/processes. Another way people might anthropomorphize God is to construe God as a minimally counterintuitive person, consistent with the claim that we form God concepts by appending God's extraordinary properties to the ordinary ontology "person." On this view, God should be attributed not only a human mind but also a human body because properties like "never dies" and "is everywhere at once" are minimally counterintuitive only with respect to the latter. There are, after all, many entities that never die (chairs, books, oceans, poems) and many entities that are everywhere at once (gravity, friction, heat, pressure), yet we do not view such entities as minimally counterintuitive because their properties do not violate their underlying ontology. A third way people might anthropomorphize God is to construe God as a full-fledged person but only at an implicit level; at an explicit level, God would be construed as an abstract entity. On this view, individuals should attribute human properties to God only when reasoning about God in implicit contexts (e.g., story-recall tasks). In explicit contexts (e.g., propertyjudgment tasks), people should deny that God possesses any human properties.

In the present set of studies, we sought to tease apart these possibilities by asking participants to decide whether two types of human properties are attributable to God: $p s y$ chological properties, pertaining to beliefs, desires, emotions, intentions, and perceptions, and physiological properties, pertaining to biological processes, biological organs, and physicality. We then compared those attributions along five dimensions: their frequency, their speed, the confidence with which they are made, the consistency with which they are made (across two sets of judgments), and their relation to participants' religiosity. The three views of how people might anthropomorphize God predict different patterns of results across those dimensions, as summarized in Table 1.

On the view that God is conceptualized as a bodiless agent, participants should be inclined to attribute psychological properties to God (attributing them at above-chance levels), but disinclined to attribute physiological properties to God (attributing them at belowchance levels). On the rare occasions that participants do attribute physiological properties to God, they should make those attributions more tentatively than they make their psychological attributions - i.e., more slowly, less confidently, and less consistently. And the reverse pattern should hold when participants deny properties to God-i.e., they should be faster, more confident, and more consistent when denying physiological properties to God than when denying psychological properties to God. Finally, it is an open question whether participants' willingness to attribute human properties to God is correlated with their religiosity, as it is unclear whether a "bodiless agent" conception of God is seen as consistent or inconsistent with those conveyed by religious doctrine. 
Table 1

Three views of how we conceptualize God - as a bodiless agent, as a minimally counterintuitive (MCI) person, and as an abstract entity at an explicit level but an ordinary person at an implicit level—and their predictions regarding our (explicit) attribution of psychological and physiological properties to God

\begin{tabular}{lll}
\hline God Concept & Attribution Dimension & \multicolumn{1}{c}{ Prediction } \\
\hline Bodiless agent & Frequency & Psychological $>$ chance $>$ physiological \\
& Speed & Psychological $>$ physiological* \\
& Confidence & Psychological $>$ physiological* \\
Consistency & Psychological $>$ physiological* \\
& Relation to religiosity & May or may not be correlated \\
FCI person & Prequency & Psychological $=$ physiological $>$ chance \\
& Speed & Psychological $=$ physiological \\
& Confidence & Psychological $=$ physiological \\
& Consistency & Psychological $=$ physiological \\
& Relation to religiosity & May or may not be correlated \\
Fmplicit person & Frequency & Psychological $=$ physiological $<$ chance \\
& Speed & Psychological $=$ physiological \\
& Confidence & Psychological $=$ physiological \\
& Consistency & More attributions under speeded conditions \\
& Relation to religiosity & Higher religiosity, fewer attributions \\
\hline
\end{tabular}

Note. *The opposite pattern is predicted for denying properties to God.

On the view that God is conceptualized as a minimally counterintuitive person, participants should be inclined to attribute both psychological and physiological properties to God. While participants should not be inclined to attribute every human property to God - some human properties are undoubtedly "negated" by God's unique, extraordinary properties - they should nonetheless be inclined to attribute both types of properties significantly more often than expected by chance. Likewise, participants should be inclined to attribute both types of properties with equal speed, confidence, and consistency, as there is no obvious reason, on this view, why one type of property should be privileged over the other. Finally, participants' willingness to attribute human properties to God may or may not be related to their religiosity, as it is unclear, on the "minimally counterintuitive person" view, whether such conceptions would be viewed as consistent or inconsistent with those conveyed by religious doctrine.

Finally, on the view that God is explicitly conceptualized as an abstract entity but implicitly conceptualized as a person, participants should be disinclined to attribute any human properties to God in an explicit property-judgment task. In other words, participants should attribute psychological and physiological properties to God at frequencies below that expected by chance. While one might argue that psychological properties are, in fact, consistent with an abstract conception of God, such properties are consistent only insofar that participants fail to conceptualize God as a truly omniscient being (see Lane, Wellman, \& Evans, 2014). Moreover, on most theologically coherent conceptions of God, God is not the type of thing that could possess either a body or a mind. Rather, God is something that exists outside space and time altogether: the "unmoved mover," the "first cause," "that than which nothing greater can be conceived" (Armstrong, 1994). 
If participants subscribe to such idealizations, then they should not only refrain from attributing human properties to God but should also show no preference for one type of property over the other in terms of how quickly, how confidently, or how consistently they make their property judgments. One caveat to this prediction is that participants should attribute more human properties to God if forced to make their judgments under time pressure, as time pressure is likely to induce conflict between participants' explicit (abstract) concepts and their implicit (anthropomorphic) concepts. Finally, participants' willingness to attribute human properties to God should be negatively correlated with their religiosity, as this view stipulates that anthropomorphic notions of God are explicitly rejected in favor of abstract, "theologically correct" notions.

In short, the literature on religious cognition supports three qualitatively different views of how people anthropomorphize God, and these views make five qualitatively different predictions about whether, and how, people will attribute psychological and physiological properties to God in an explicit property-judgment task. While individuals no doubt differ in their particular (idiosyncratic) conceptions of God, we sought to determine whether God concepts are best described as person-based or agent-based on the whole, as well as whether that description remains valid across differences in participants' age, gender, religion, and degree of religiosity.

\section{Study 1}

In our first study, we sought to explore the proportionate role of several fundamental human properties in Western adults' conceptions of God. The specific questions of interest were (a) To what extent is God attributed psychological properties as compared to physiological properties? and (b) How are these attribution patterns shaped by participants' religiosity? Our initial investigation of anthropomorphic attributions did not include measures of speed, confidence, or consistency, which were only included in Studies 2 and 3. While we predicted that participants would attribute more psychological properties to God than physiological properties, consistent with other research (e.g., Shtulman, 2008), we had no definitive expectations as to whether those attributions would be uniform across the various properties within those categories or whether they would be correlated with religiosity.

\subsection{Method}

\subsubsection{Participants}

The participants in Study 1 were 1,525 Finnish adults. Five additional adults took the survey but did not complete all measures and were thus excluded from the final dataset. Their mean age was 27.7 years (range 15-73); 1,117 of them were female, 389 were male, and 19 did not report their gender. Participants' educational background ranged as follows: elementary school (3.3\%), vocational school (4.5\%), upper secondary school $(50.0 \%)$, polytechnic $(8.7 \%)$, university $(29.6 \%)$, and other $(3.1 \%)$. At the time of the 
survey, $23.1 \%$ of participants were working, $60.9 \%$ were enrolled at a university, and $4.4 \%$ were attending some other type of school. The rest $(10.6 \%)$ were otherwise occupied.

In terms of religious background, most participants (69.6\%) reported that they were Lutheran; some (24.6\%) reported no denominational affiliation; and a few (1.1\%) did not report their denomination. Other participants reported that they were Orthodox (1.2\%), Evangelical (0.6\%), Catholic (0.5\%), Muslim (0.3\%), Jehovah's Witness $(0.1 \%)$, Adventist $(0.1 \%)$, Mormon $(0.1 \%)$, or some other denomination (2\%). Originally, 3,063 individuals took part in this study, which also included other scales and tasks not reported here. Only those who considered themselves "even a bit religious" were included in the present study because only they were asked to complete the property-judgment task.

\subsubsection{Procedure}

The participants were recruited via electronic student mailing lists and five Internet discussion forums. The respondents were told that the study concerned beliefs, worldviews, and cognition and were referred to an online questionnaire, which included other assessment scales than those reported here. Confidentiality and voluntariness of participation were stressed, and the respondents were given between 3 and 4 weeks' time to participate in the study. For compensation, all participants were given a personal-value or worldview profile based on scales included in the questionnaire (e.g., Janoff-Bulman, 1989).

\subsubsection{Measures}

In the first part of the study, participants decided whether each of 48 human properties could or could not be attributed to God. They registered their judgments as agreement or disagreement with statements of the form "God [property]" (e.g., "God can be happy" or "God has a brain"). The properties, which are displayed in Table 2, included 23 psychological properties (related to beliefs, desires, emotions, intentions, and perceptions) and 25 physiological properties (related to biological processes, biological organs, and physicality). Participants also judged the attributability of seven theological properties derived from Christian doctrine, which, for this sample, represented the most relevant religious doctrine. Those properties were "is almighty," "is omniscient," "is the creator," "is triune," "is father," "is the king of kings," and "forgives sin." They were derived from an earlier study on God concepts by Lindeman, Pyysiäinen, and Saariluoma (2002) and were used as a secondary measure of religiosity.

Our primary measure of religiosity was a 16-item version of the Fetzer Brief Multidimensional Measure of Religiousness/Spirituality (taken from Neff, 2006). This scale includes measures of daily spirituality, positive religious coping, participation in public and private worship, and self-reported religiosity. Sample items are "I believe in a God who watches over me," "I feel God's presence," and "I find strength and comfort in religion." Participants rated their agreement with all statements on a scale from 1 ("strongly disagree") to 5 ("strongly agree"). Four items from the original scale that were not specifically about religion were excluded because even atheists could agree with them (e.g., "I 
Table 2

The percentage of participants in Study 1 who attributed each property to God and the correlations between those attributions and participants' religiosity (Fetzer score)

\begin{tabular}{|c|c|c|}
\hline Property & Percentage $(\%)$ & Correlation $(r)$ \\
\hline \multicolumn{3}{|l|}{ Psychological (mind-dependent) properties } \\
\hline \multicolumn{3}{|l|}{ Beliefs } \\
\hline Knows things & 70.6 & $.59 * * *$ \\
\hline Knows what's what & 69.9 & $.60 * * *$ \\
\hline Is aware of things & 69.2 & $.59 * * *$ \\
\hline \multicolumn{3}{|l|}{ Desires } \\
\hline Can aim at something & 63.1 & $.51 * * *$ \\
\hline Can want & 60.3 & $.50 * * *$ \\
\hline Can strive for something & 57.0 & $.52 * * *$ \\
\hline Can desire something & 51.8 & $.55^{* * *}$ \\
\hline \multicolumn{3}{|l|}{ Intentions } \\
\hline Can communicate & 65.2 & $.63 * * *$ \\
\hline Can commit planned actions & 62.8 & $.60 * * *$ \\
\hline Can be goal oriented & 60.6 & $.53 * * *$ \\
\hline Can make plans & 59.9 & $.54 * * *$ \\
\hline Is capable of reciprocal actions & 55.6 & $.46^{* * *}$ \\
\hline \multicolumn{3}{|l|}{ Emotions } \\
\hline Can be satisfied & 59.1 & $.56 * * *$ \\
\hline Can be happy & 53.9 & $.49 * * *$ \\
\hline Can be worried & 52.7 & $.48 * * *$ \\
\hline Can be sad & 52.3 & $.54 * * *$ \\
\hline \multicolumn{3}{|l|}{ Perception } \\
\hline Can hear & 58.6 & $.54 * * *$ \\
\hline Can see & 58.1 & $.53 * * *$ \\
\hline Can sense warmth & 29.6 & $.36 * * *$ \\
\hline Can smell & 28.8 & $.38 * * *$ \\
\hline Can sense coldness & 26.5 & $.35 * * *$ \\
\hline Can sense pain & 24.9 & $.34 * * *$ \\
\hline Can taste & 22.4 & $.34 * * *$ \\
\hline \multicolumn{3}{|l|}{ Physiological (body-dependent) properties } \\
\hline \multicolumn{3}{|l|}{ Biological processes } \\
\hline Lives & 53.8 & $.58 * * *$ \\
\hline Can recover from an illness & 19.9 & $.14 * * *$ \\
\hline Can breathe & 18.9 & $.29 * * *$ \\
\hline Can eat food & 14.0 & $.24 * * *$ \\
\hline Can drink & 14.0 & $.25 * * *$ \\
\hline Can reproduce & 12.0 & $.16^{* * *}$ \\
\hline Can transmit a disease to somebody & 10.4 & .04 \\
\hline Can die & 9.1 & .00 \\
\hline Can grow old & 8.8 & $.06^{*}$ \\
\hline Can become ill & 7.1 & $.06^{*}$ \\
\hline \multicolumn{3}{|l|}{ Biological organs } \\
\hline Has a heart & 24.0 & $.31 * * *$ \\
\hline
\end{tabular}


Table 2. (continued)

\begin{tabular}{lcc}
\hline Property & Percentage $(\%)$ & Correlation $(r)$ \\
\hline Has a brain & 19.5 & $.20^{* * *}$ \\
Has hands and feet & 17.6 & $.24^{* * *}$ \\
Has eyelids & 15.0 & $.22^{* * *}$ \\
Has earlobes & 13.5 & $.20^{* * *}$ \\
Has lungs & 9.9 & $.20^{* * *}$ \\
Has bones & 9.1 & $.18^{* * *}$ \\
Has a digestive system & 6.2 & $.16^{* * *}$ \\
Has a blood-vascular system & 6.2 & $.15^{* * *}$ \\
Physicality & & \\
Exerts force & 74.7 & $.53^{* * *}$ \\
Has a stable existence & 69.8 & $.57^{* * *}$ \\
Can make a material object move & 64.5 & $.67^{* * *}$ \\
Has an independent existence & 61.5 & $.52^{* * *}$ \\
Has a weight that can be measured by kg & 4.6 & $.08^{* * *}$ \\
Has a height that can be measured by cm & 4.5 & $.10^{* * *}$ \\
\hline
\end{tabular}

Note. ${ }^{*} p<.05, * * * p<.001$.

feel a deep sense of responsibility for reducing pain and suffering in the world," "I have forgiven those who hurt me").

\subsection{Results}

\subsubsection{Property attributions}

As expected, participants made significantly more psychological attributions than physiological attributions. On average, they attributed $53 \%$ of psychological properties to God but only $22 \%$ of physiological properties to God - a highly significant difference (pairedsamples $t(1524)=45.32, p<.001)$. These attributions are broken down by property in Table 2. A majority of psychological properties were attributed by a majority of participants, with the only exceptions being the five perceptual properties "can sense warmth," "can sense coldness," "can sense pain," "can smell," and "can taste," which were each attributed to God by $20 \%-30 \%$ of participants. In contrast, a majority of physiological properties were denied to God by a majority of participants, with the only exceptions being the properties "lives," "exerts force," "has a stable existence," "can make a material object move," and "has an independent existence," which were each attributed to God by $50 \%-75 \%$ of participants. Also included in Table 2 are correlations between participants' propensity to attribute each property and their self-reported religiosity, as measured by the Fetzer scale. All but two correlations were significant, indicating that highly religious participants were more likely to attribute human properties to God than were less religious participants. These correlations are investigated in more detail below.

To explore the dimensions underlying participants' attributions, we submitted those attributions to the ALSCAL Multidimensional Scaling algorithm in sPSs 21, with Euclidean distances adopted as our scaling metric. The results of this analysis are displayed in 
Fig. 1. The majority of properties fell into one of two clusters: a cluster of psychological properties in the upper left quadrant and a cluster of physiological properties in the upper right quadrant. Two exceptions to this rule were the five psychological properties noted above for their low attribution rates, which clustered closer to the physiological properties than to the other psychological properties, and the five physiological properties noted above for their high attribution rates, which clustered closer to the psychological properties than to the other physiological properties. In addition, the four emotional properties "can be worried," "can be happy," "can be sad," and "can desire something" clustered slightly above the other psychological properties, along with the intentional property "is capable of reciprocal actions." Based on this array of properties, the horizontal axis of Fig. 1 would appear to represent the degree to which a property is dependent on a biological body (above and beyond a physical form), and the vertical axis would appear to represent the property's concreteness.

Based on this clustering pattern, one could argue that the perceptual properties "can sense warmth," "can sense coldness," "can sense pain," "can smell," and "can taste" should be reclassified as physiological properties, but there are several considerations that militate against this conclusion. First, participants attributed these properties to God more than twice as often as they attributed the 20 physiological properties with which they clustered - a highly significant difference $(M=0.26$ vs. $0.10, t(1524)=22.54, p<.001)$. Second, reclassifying these properties based on their proximity to other properties in the multidimensional scaling solution would suggest that the cluster of physiological properties

\section{OPsych OPhys}

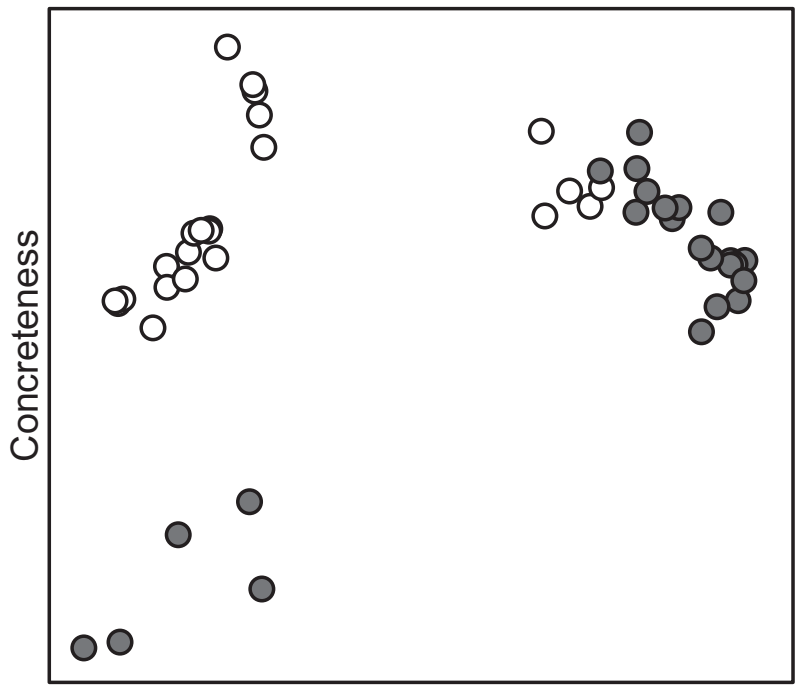

Body-dependence

Fig. 1. Multidimensional scaling of participants' attribution patterns for the 23 psychological properties (Psych) and 25 physiological properties (Phys) in Study 1. 
in the lower left quadrant should be reclassified as well, but doing so would lead to a theoretically incoherent set of psychological properties. Third, not all perceptual properties clustered more closely with the physiological properties; "can see" and "can hear" clustered more closely with the other psychological properties, and certainly properties like "can smell" and "can taste" have more in common (theoretically) with "can see" and "can hear" than they do with "has bones" and "has a digestive system." Fourth, the analyses performed in Studies 2 and 3 require variation in attributions within each domain of properties, and removing five of the seven perceptual properties from the psychological domain would reduce much of that variation. For these reasons, we continued to classify all perceptual properties as psychological properties in subsequent analyses.

\subsubsection{Relations to religiosity}

Participants' property attributions are displayed as a function of religiosity in Fig. 2. For the purposes of this analysis, participants were split into four groups: those who scored between 1 and 2 on the Fetzer scale ("group 1," $n=484$ ), those who scored between 2 and 3 ("group 2," $n=420$ ), those who scored between 3 and 4 ("group 3," $n=391$ ), and those who scored between 4 and 5 ("group 4," $n=230$ ), with each division inclusive of the lowest score in that range. We compared the frequency of psychological and physiological attributions across Fetzer groups, using a repeated-measures analysis of variance (ANOVA). This analysis revealed a significant effect of Fetzer group $\left(F(3,1521)=282.61, p<.001\right.$, partial $\left.\eta^{2}=.36\right)$, a significant effect of property type

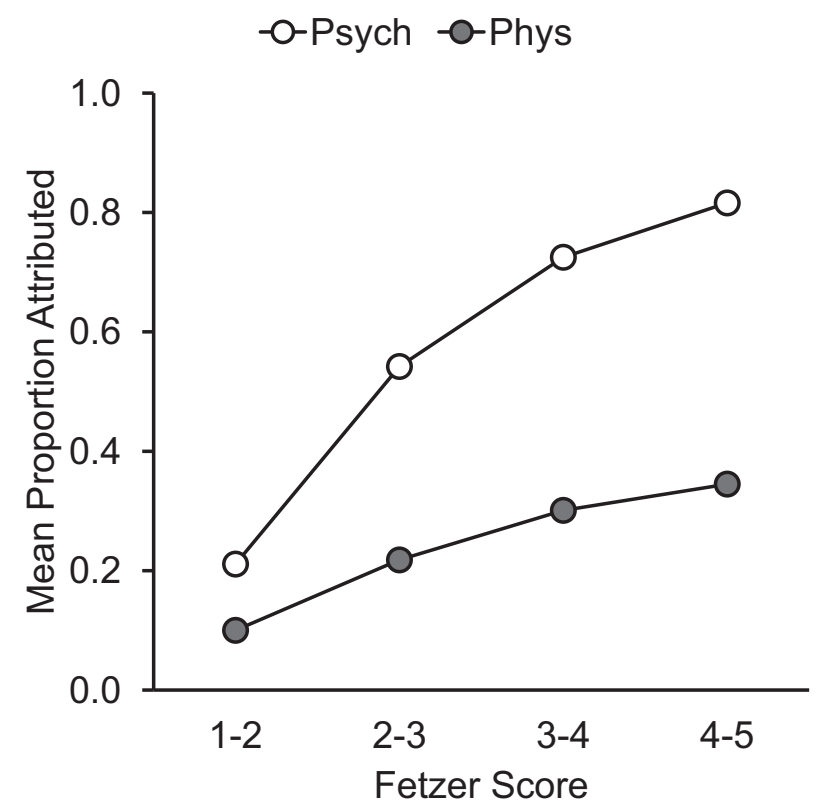

Fig. 2. Mean proportion of psychological and physiological properties attributed to God as a function of religiosity (Fetzer score) in Study 1. All $S E<0.02$. 
$\left(F(3,1521)=3,186.89, p<.001\right.$, partial $\left.\eta^{2}=.68\right)$, and a significant interaction between the two $\left(F(3,1521)=206.89, p<.001\right.$, partial $\left.\eta^{2}=.29\right)$.

At all levels of religiosity, participants attributed significantly more psychological properties to God than physiological properties (group 1: $t(483)=11.06, p<.001$; group $2: t(419)=27.94, p<.001$; group 3: $t(390)=39.20, p<.001$; group $4: t(229)=35.28$, $p<.001$ ), though the magnitude of that difference increased with religiosity. More important, the proportion of physiological properties attributed to God was significantly below 0.5 - the proportion expected by chance-for all four groups (group 1: $t$ $(483)=54.46, p<.001$; group 2: $t(419)=39.91, p<.001 ;$ group $3: t(390)=19.01$, $p<.001$; group 4: $t(229)=24.21, p<.001)$, and the proportion of psychological properties attributed to God was significantly above 0.5 for all but group 1 (group 2: $t$ $(419)=2.66, p<.01 ;$ group 3: $t(390)=17.20, p<.001 ;$ group $4: t(229)=10.59$, $p<.001$ ). Thus, the prediction that participants would attribute to God (a) more psychological properties than expected by chance and (b) fewer physiological properties than expected by chance was confirmed for all but the least religious participants, who attributed few properties to God altogether.

While one might be tempted to interpret the performance of the least religious participants as conforming to the "implicit person" hypothesis (in that they refrained from attributing anthropomorphic properties to God because they construe God as a person only at an implicit level), it should be noted that these participants did not attribute many theological properties to God either. In fact, they attributed significantly fewer theological properties to God than did participants in the other Fetzer groups $(M=0.12$ vs. $0.72, t$ $(1523)=36.22, p<.001)$, implying that they were not as engaged with the task overall.

As can be seen from Fig. 2, property attributions for both types of human propertiespsychological and physiological — tracked religiosity. The correlations among these measures are displayed in the top half of Table 3, along with correlations pertaining to the proportion of theological properties attributed to $\operatorname{God}(M=0.53, S D=0.41)$. All correlations were strong and positive, indicating that participants with high religiosity attributed both more human properties and more theological properties to God than did those with low religiosity. Moreover, the magnitude of the correlations between religiosity and anthropomorphic attributions was comparable to the magnitude of the correlations between anthropomorphic attributions and theological attributions, suggesting that anthropomorphic conceptions of God are perceived to be as consistent with theological conceptions of God as they are with strong religious beliefs.

Finally, it is worth noting that the correlations in Table 3 remained virtually unchanged when controlling for age and gender, as all zero-order correlations between age and gender and the variables in Table 3 were no larger than $r(1523)=.16$. Likewise, correlations between theological attributions and anthropomorphic attributions remained strong and significant when controlling for religiosity (psychological attributions: $r(1523)=.54$, $p<.001$; physiological attributions: $r(1523)=.31, p<.001)$, indicating that the overlap in theological attributions and anthropomorphic attributions was not driven solely by religious belief; participants of all levels of religiosity appeared to view these properties as compatible. 
Table 3

Correlations among participants' psychological attributions, physiological attributions, theological attributions, and religiosity (Fetzer score) in Studies 1 and 2

\begin{tabular}{llllll}
\hline Study & \multicolumn{1}{c}{ Measure } & 1 & \multicolumn{1}{c}{2} & \multicolumn{1}{c}{3} & \multicolumn{1}{c}{4} \\
\hline 1 & 1. Psychological attributions & 1.00 & $0.73^{* * *}$ & $0.76^{* * *}$ & $0.64^{* * *}$ \\
2. Physiological attributions & & 1.00 & $0.53^{* * *}$ & $0.46^{* * * *}$ \\
3. Theological attributions & & & 1.00 & $0.80^{* * * *}$ \\
& 4. Religiosity & & & & 1.00 \\
1. Psychological attributions & 1.00 & $0.66^{* * *}$ & $0.50^{* * *}$ & $0.38^{* * *}$ \\
& 2. Physiological attributions & & 1.00 & $0.49^{* * *}$ & $0.29^{* *}$ \\
3. Theological attributions & & & 1.00 & $0.51^{* * *}$ \\
& 4. Religiosity & & & 1.00 \\
\hline
\end{tabular}

Note. ${ }^{* *} p<.01,{ }^{* * *} p<.001$.

\subsection{Discussion}

The objectives of Study 1 were to clarify the dimensions along which God is, and is not, anthropomorphized and to determine whether, and how, anthropomorphism relates to religiosity. Three main findings emerged. First, psychological attributions to God were significantly more common than physiological attributions. While most participants agreed that God is aware of things, that God has aims and strivings, that God can communicate and commit planned actions and that he can be satisfied, happy, or sad, very few agreed that God partakes in biological processes like eating or drinking, that God possesses biological organs like a heart or a brain, or that God has material dimensions that can be physically measured. Indeed, 18 of the 23 psychological properties (or 78\%) were attributed to God by over half of the individuals sampled, but only 5 of the 25 physiological properties (or 20\%) met this same criterion. This difference was borne out by the multidimensional scaling of participants' full attribution patterns, which revealed that participants' attributions were determined mainly by the extent to which the properties under considerations pertained to a (biological) body.

Second, participants' physiological attributions to God, though less frequent than their psychological attributions, were not absent altogether. While most participants declined to attribute specific, concrete physiological properties, like "can recover from an illness" or "has a digestive system," they readily attributed three other properties: "lives," "exerts force," and "has a stable existence" (along with two permutations of this idea: "has an independent existence" and "can make a material object move"). One explanation for these attributions is that participants interpreted such properties as pertaining to God's mind, not God's body. One can be a force solely in a psychological sense (e.g., "she is a force for good," "he is a force to be reckoned with"), just as one can "live" or "exist" solely in a psychological sense (e.g., "her ideas live on," "he will continue to exist in our memories"). Still, it is unclear why participants would have interpreted these three properties in a psychological sense but not any of the other properties amenable to this kind of interpretation (e.g., "can grow old," "can become ill"). 
An alternative explanation is that these three properties are so fundamental of any animate, self-directed entity that participants saw no inconsistency in attributing them to a bodiless agent. Consistent with this idea, research on the development of intuitive biology has found that children attribute life to living (and sometimes nonliving) entities before they understand that specific biological organs and specific metabolic processes are prerequisites for life (Carey, 1985; Piaget, 1929/1951; Slaughter \& Lyons, 2003). Likewise, research on the developmental origins of intuitive physics has found that, while infants appreciate that physical objects have a stable, independent existence and can exert force on other objects (Leslie, 1994; Spelke, 1990), children do not begin to appreciate more specific properties of matter, like buoyancy or density, until early adolescence (Nakhleh, Samarapungavan, \& Saglam, 2005; Smith, 2007). Thus, participants' tendency to endorse "God can live" but not "God can breathe" or their tendency to endorse "God can make a material object move" but not "God has a weight that can be measured in kilos" may be a developmental remnant of learning the most basic properties of biological and physical phenomena before learning more particular, causally specific properties.

Third, and perhaps most notable, participants' tendency to attribute anthropomorphic properties to God was robustly correlated with both their religiosity and their tendency to attribute theological properties to God (e.g., "is almighty," "is triune"). These results cast doubt on the claim that anthropomorphic conceptions of God and theological conceptions of God are distinct and contradictory-an entailment of the "implicit person" view of how we anthropomorphize God. While some aspects of anthropomorphic conceptions may be viewed as contradictory with theological conceptions, other aspects may be viewed as quite compatible. For instance, many people may construe human abilities (e.g., beliefs, intentions) as compatible with theological conceptions of God but construe human constraints (e.g., limited focus of attention, limited range of knowledge) as incompatible, both in their application and in their acquisition (Barrett et al., 2001; Knight et al., 2004; Lane et al., 2014). Additional research is needed to tease apart which anthropomorphic properties are deemed compatible with theological descriptions of God and which are not. Overall, however, most properties appear to be deemed compatible.

One additional finding that needs clarification is the apparent inconsistency between our finding that anthropomorphism tracked religiosity and Willard and Norenzayan's (2013) finding that anthropomorphic tendencies are not correlated with religious belief. A key difference between our study and theirs is that we measured anthropomorphism in the context of God concepts, whereas Willard and Norenzayan measured anthropomorphism as a general cognitive bias (as in the tendency to attribute consciousness to robots or the tendency to attribute free will to fish; Waytz, Cacioppo, \& Epley, 2010). Given that these two measures bear different relations to religious belief, it would appear that variation in anthropomorphism as a cognitive bias does not track variation in anthropomorphism as a means of conceptualizing God. Our general, everyday bias to project human properties onto nonhuman entities may well have given rise to anthropomorphic concepts of God historically, but that bias does not appear to be what drives adherence to those concepts psychologically. 


\section{Study 2}

The results from Study 1 were most consistent with a "bodiless agent" view of how we anthropomorphize God. In Study 2, we sought further support for this view by measuring additional dimensions of participants' property judgments: their speed, their consistency, the confidence with which they are made, and the means by which they are justified. Our prediction was that, if psychological properties (on the whole) are cognitively easier to attribute to God than are physiological properties (on the whole), then participants should attribute them faster, more consistently, and more confidently. And participants should exhibit the opposite pattern of results when denying properties to God, as noted above. It was also predicted that participants would provide different types of justifications for their psychological and physiological judgments, if the former are attributed "by default" whereas the latter are attributed only with additional consideration. The nature of that difference, however, was unclear at the outset.

\subsection{Method}

\subsubsection{Participants}

The participants in Study 2 were 99 undergraduates at Occidental College recruited from psychology courses and compensated with course credit. Pilot testing revealed that a sample of this size was sufficiently large to detect the effects of interest. A majority (70\%) were female, and 26\% self-identified as Protestant, 15\% as Catholic, $13 \%$ as Jewish, and 7\% as something else (e.g., Buddhist, Quaker). The remaining 39\% reported no current religious affiliation, though the majority of this group (86\%) indicated some level of religiosity on the Fetzer scale.

\subsubsection{Procedure}

Participants completed a three-part survey administered in MediaLab v2012. In the first part of the survey, participants were shown one of the 48 psychological or physiological properties displayed in Table 2 and asked to determine, as quickly as possible, whether that property was true of God. The ordering of properties was randomized across participants. Participants registered their response by pressing 1 for "true" and 2 for "false," and their response times were recorded in milliseconds. The mean response time across items and across subjects was $2,827 \mathrm{~ms}$, and all response times that fell more than two standard deviations beyond this mean ( 84 out of 4,653 , or $1.8 \%$ ) were eliminated from the dataset. Following each judgment, participants were asked to rate their confidence in that judgment on a scale from 1 to 5 , with 1 labeled as "not confident;" 2 , " $25 \%$ confident," 3, "50\% confident;" 4, "75\% confident;" and 5, "100\% confident." Participants were informed that, while their judgments were being timed, their confidence ratings were not, thus affording a brief respite between judgments.

In the second part of the survey, participants were shown the same 48 properties from the first part of the survey and were asked to make property judgments once again. Doing 
so allowed us to assess the consistency of those judgments across two blocks of randomly ordered properties. Participants were informed that their judgments in the second part of the survey were not being timed and were thus urged to take as much time as needed. Participants were also now prompted to provide justifications for their judgments, and those justifications were analyzed in terms of a coding scheme described below. In the third part of the survey, participants completed the same 16-item version of the Fetzer scale of religiosity/spirituality administered in Study 1. They also entered their age, gender, and religious affiliation.

It should be noted that the entire survey was prefaced with the following instruction: "You do not need to believe that God exists in order to complete the survey. Rather, you simply need to decide whether the concept "God"- - as you understand the concept-can or cannot be described by the property at hand." This instruction was intended to assure participants who did not believe in God that they could still participate, as stipulated by the Occidental College Institutional Review Board. Preliminary analyses revealed no reliable differences in attribution patterns between those who endorsed God's existence and those who did not (as measured by the Fetzer scale), so we collapsed across that distinction when running our final analyses.

\subsection{Results}

\subsubsection{Property attributions}

Consistent with Study 1, participants attributed psychological properties to God at a frequency significantly above that expected by chance $(M=0.72, t(98)=8.01, p<.001)$ and attributed physiological properties to God at a frequency significantly below that expected by chance $(M=0.35, t(98)=6.21, p<.001)$. The difference between psychological and physiological attributions was also significant $(t(98)=17.24, p<.001)$. And this difference was observed for participants of all levels of religiosity: those who scored between 1 and 2 on the Fetzer scale $(M=0.62$ vs. $0.27, t(24)=7.14, p<.001)$, those who scored between 2 and $3(M=0.66$ vs. $0.32, t(38)=11.34, p<.001)$, those who scored between 3 and $4(M=0.82$ vs. $0.44, t(18)=7.16, p<.001)$, and those who scored between 4 and $5(M=0.88$ vs. $0.46, t(15)=9.08, p<.001)$.

We explored these effects further using repeated-measures ANOVA in which the property type was treated as a within-participants factor and Fetzer group was treated as a between-participants factor. This analysis revealed a significant effect of Fetzer group ( $F$ $(3,95)=5.48, p<.01$, partial $\left.\eta^{2}=.15\right)$ and a significant effect of property type $(F(1$, $95)=271.96, p<.001$, partial $\left.\eta^{2}=.74\right)$ but no interaction between them $(F(3$, $95)=0.43, p=.73$, partial $\left.\eta^{2}=.01\right)$. Thus, in contrast to Study 1 , the gap between psychological and physiological attributions remained relatively constant across Fetzer groups, possibly because participants in Study 2 were encouraged to respond regardless of the strength of their religious beliefs.

Also consistent with Study 1, participants' attributions varied within domains in predictable ways. The five psychological properties attributed least frequently to God were the perceptual properties "can taste" (attributed by $41 \%$ of participants), "can sense 
coldness" (47\%), "can smell" (51\%), "can sense warmth" (57\%), and "can sense pain" (60\%). And the five physiological properties attributed most frequently to God were those that describe human physiology at a very general level: "can make a material object move" (attributed by 54\% of participants), "lives" (62\%), "has a stable existence" (71\%), "has an independent existence" (75\%), and "exerts force" (79\%). The nature of these attributions is explored in more detail below.

\subsubsection{Response times}

Response times for the psychological properties $(M=2.59 \mathrm{~s}, S D=0.78)$ were, on the whole, highly similar to those for the physiological properties $(M=2.65 \mathrm{~s}, S D=0.73)$. Nevertheless, response times varied by judgment type across the two domains, as shown in Fig. 3. When participants attributed properties to God, they were faster to do so for psychological properties than for physiological properties, yet when they denied properties to God, they were faster to do so for physiological properties than for psychological properties.

These effects were confirmed with a repeated-measures ANOVA in which both property type (psychological vs. physiological) and judgment type (attributed vs. denied) were treated as within-participants factors. This analysis revealed no effect of property type $(F$ $(1,98)=1.24, p=.27$, partial $\left.\eta^{2}=.01\right)$ or judgment type $(F(1,98)=0.39, p=.53$, partial $\left.\eta^{2}<.01\right)$, but it did reveal a significant interaction between the two $(F(1$, $98)=20.57, p<.001$, partial $\left.\eta^{2}=.17\right)$. This interaction suggests that participants' default stance toward the psychological properties was to attribute those properties but their default stance toward the physiological properties was to deny those properties; making the opposite judgment required some additional degree of thought or effort.

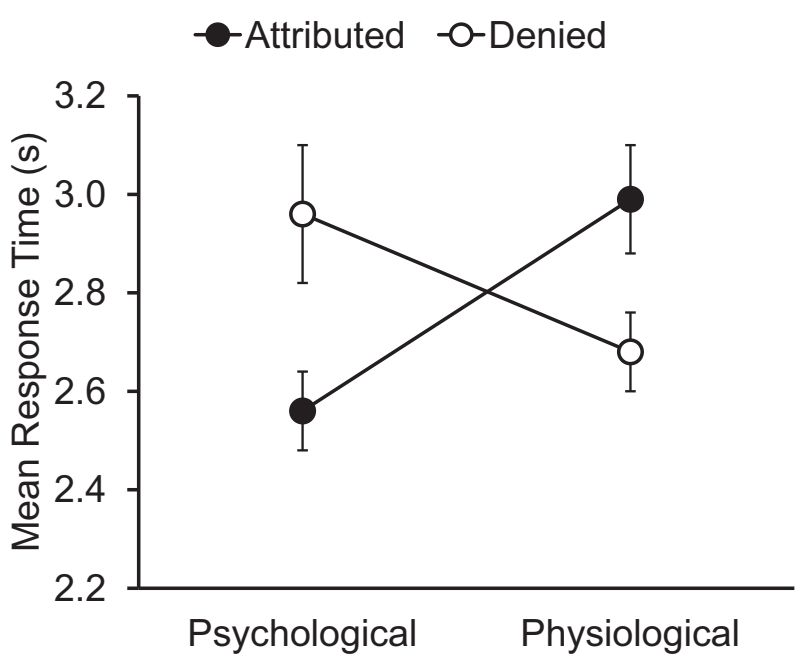

Fig. 3. Mean response times (in seconds) for property judgments in Study 2, analyzed by property type and judgment type. Error bars represent $S E$. 
Similar effects were observed at the level of individual properties. Fig. 4 displays mean differences in response times between those who denied each property to God and those who attributed that property to God as a function of the overall percentage of participants who attributed the property (where each dot represents a different property). Positive differences indicate that participants took longer to deny the property than to attribute it, and negative differences indicate that participants took longer to attribute the property than to deny it. Response-time differences in the psychological properties were mostly positive (17 of 26 , or $65 \%$, were positive), whereas response-time differences in the physiological properties were mostly negative (14 of 21 , or $66 \%$, were negative). A chi-square analysis of the ratio of positive response-time differences to negative response-time differences in each domain confirmed the reliability of this effect $\left(\chi^{2}=4.78, p<.05\right)$.

Also evident from Fig. 4 is that response-time differences tracked total property attributions. The frequency with which each property was attributed to God predicted how much longer it took participants to deny that property to God than to attribute it ( $r$ $(46)=.56, p<.001)$. For instance, the psychological property "can see" was attributed to God by $81 \%$ of participants and took, on average, $1.00 \mathrm{~s}$ longer to deny to God than to attribute to God, whereas the physiological property "can reproduce" was attributed to God by only $26 \%$ of participants and took, on average, $1.19 \mathrm{~s}$ longer to attribute to God

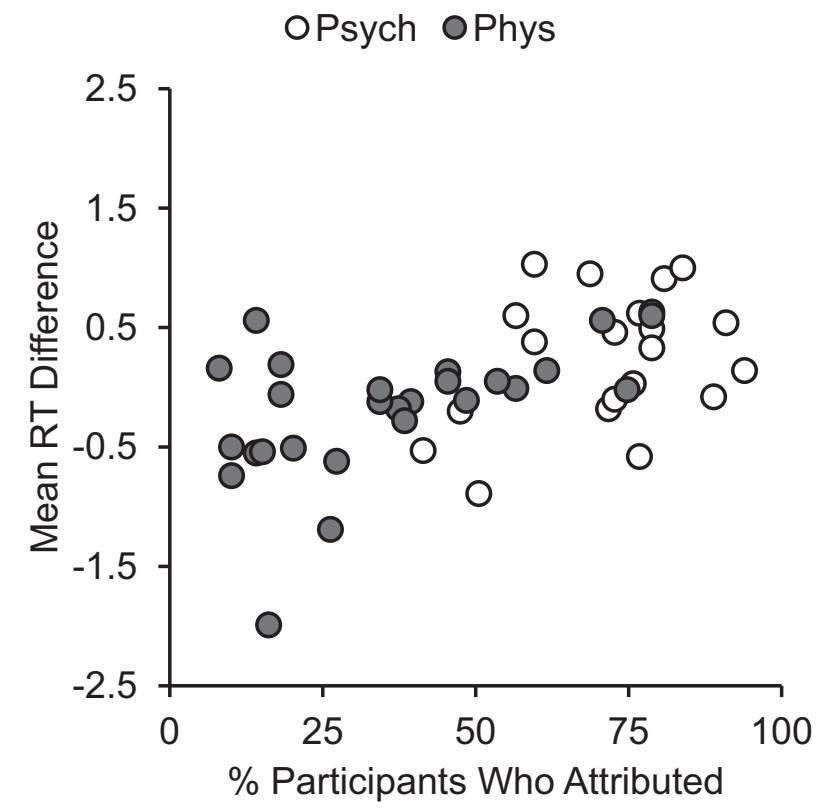

Fig. 4. Mean differences in response times between those who denied each psychological (Psych) and physiological (Phys) property to God and those who attributed the property to God as a function of the overall percentage of participants who attributed the property. Positive differences indicate that participants took longer to deny the property than to attribute it, and negative differences indicate that participants took longer to attribute the property than to deny it. 
than to deny to God. These findings indicate that the within-participant interaction between property type and judgment type, displayed in Fig. 3, held at the level of individual properties as well, albeit as a between-participants effect.

\subsubsection{Confidence ratings}

Participants' confidence ratings patterned similarly to their response times, as shown in Fig. 5. A repeated-measures ANOva of the same type used to analyze response times was used to analyze confidence ratings. This analysis revealed no effect of property type $(F(1$, $98)=0.12, p=.73$, partial $\left.\eta^{2}<.01\right)$, but a marginal effect of judgment type $(F(1$, $98)=3.86, p=.05$, partial $\left.\eta^{2}=.04\right)$, as participants were slightly more confident when attributing properties to $\operatorname{God}(M=3.9, S D=0.7)$ than when denying properties to God $(M=3.8, S D=0.8)$. More importantly, it revealed a significant interaction between property type and response type $\left(F(1,98)=53.43, p<.001\right.$, partial $\left.\eta^{2}=.35\right)$ such that confidence was highest for psychological properties when those properties were attributed to God, but was highest for physiological properties when those properties were denied to God.

\subsubsection{Inter-trial consistency}

Participants completed the property-attribution task twice, once under the prompt to respond as quickly as possible and once under the prompt to take as much time as needed. The proportion of properties for which participants provided the same judgment across trials is displayed in Fig. 6 as a function of property and judgment types. A repeated-measures ANOVA revealed similar findings to those revealed above: Response consistency did not vary either by property type $(F(1,98)=0.52, p=.47$, partial $\left.\eta^{2}=.01\right)$ or by judgment type $\left(F(1,98)=0.42, p=.52\right.$, partial $\left.\eta^{2}<.01\right)$ but did vary

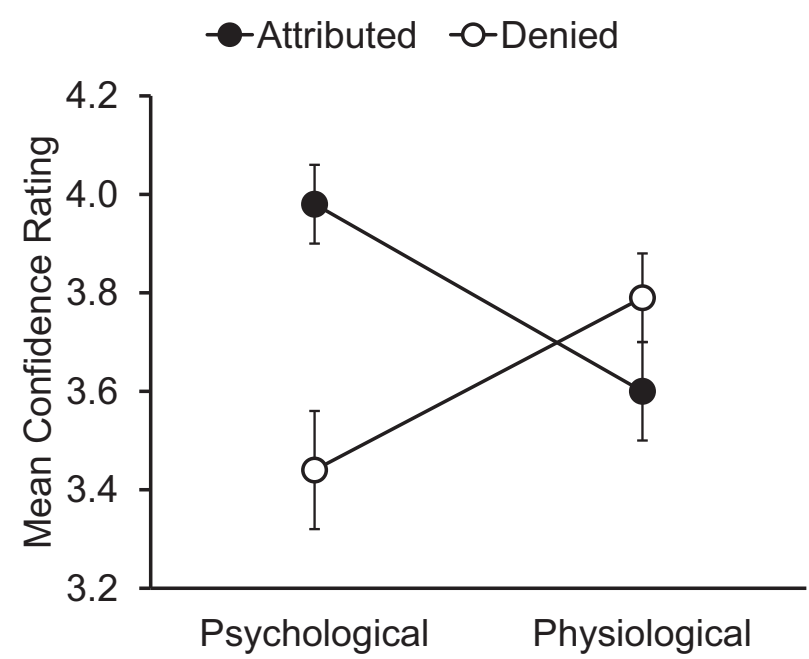

Fig. 5. Mean confidence ratings (out of five) for property judgments in Study 2, analyzed by property type and judgment type. Error bars represent $S E$. 


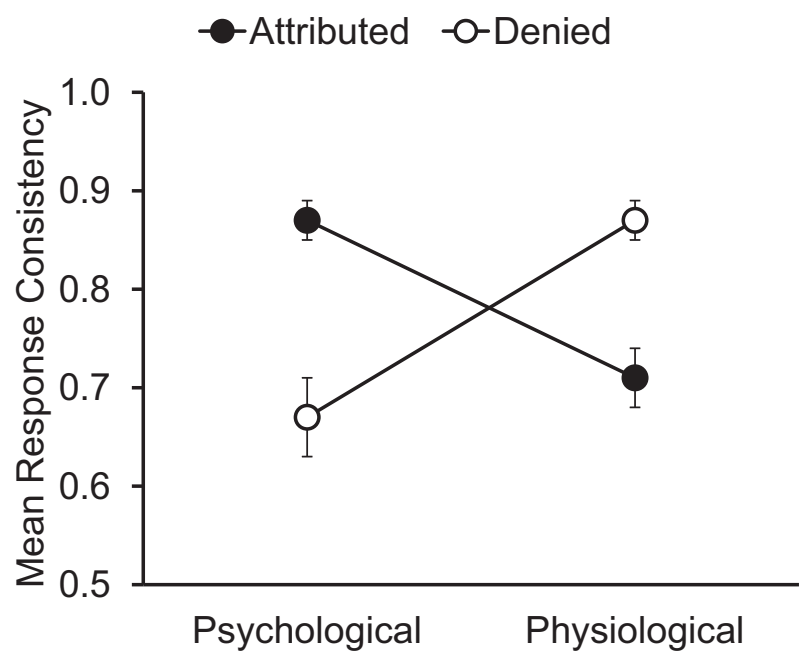

Fig. 6. Mean proportion of consistent responses across trials for property judgments in Study 2, analyzed by property type and judgment type. Error bars represent $S E$.

as a function of their interaction $\left(F(1,98)=53.46, p<.001\right.$, partial $\left.\eta^{2}=.35\right)$. For psychological properties, participants changed their minds about denying those properties to God more often than they changed their minds about attributing them to God; for physiological properties, the opposite was true.

We should note that the proportion of properties attributed to God in the second block of judgments was highly similar to the proportion attributed in the first block. Under speeded conditions, participants attributed, on average, $72 \%$ of the psychological properties and 35\% of the physiological properties. Under nonspeeded conditions, those percentages were $71 \%$ and $32 \%$, respectively. Paired-samples $t$ tests revealed that the decrease in attributions was not significant for the psychological properties $(t(98)=0.32, p=.75)$, but it was significant for the physiological properties $(t(98)=2.57, p<.05)$. Nevertheless, the difference was small: $3 \%$, or less than a single property.

\subsubsection{Justifications}

In the second (unspeeded) block of property judgments, participants provided justifications for those judgments. Justifications were sorted into one of three categories: comparisons to humans, appeals to God's properties, or inferences from God's actions. Comparisons to humans emphasized similarities between God and humans in the case of properties attributed to God (e.g., "God has human senses") or differences between God and humans in the case of properties denied to God (e.g., "God doesn't experience the world like humans do"). Appeals to God's properties highlighted some aspect of God's unique ontology that was either consistent with the property at hand (e.g., "God can influence the world by any means") or inconsistent with that property (e.g., "God doesn't live because God doesn't die; God simply exists"). And inferences from God's actions specified how the property at hand was either presupposed by something God is purported to 
do (e.g., "If God can listen to our prayers then I would assume that he can hear them") or precluded by something God is purported to do (e.g., "God cannot transmit a disease because he never harms others"). The reliability of this coding scheme was assessed by comparing the codes of two independent judges for a quarter of the 4,653 justifications provided. Agreement was high $(86 \%$, Cohen's $\kappa=.79)$.

Overall, $44 \%$ of justifications were coded as comparisons to humans, $27 \%$ as appeals to God's properties, and $24 \%$ as inferences from God's actions. The remaining $5 \%$ did not contain any codable information. Domain differences in the provision of each type of justification are displayed in Table 4. When justifying judgments for psychological properties, participants tended to cite inferences from God's actions and appeals to God's properties, but when justifying judgments for physiological properties, participants tended to cite comparisons to humans. In other words, participants' justifications for psychological properties tended to be God-based, whereas their justifications for physiological properties tended to be human-based.

This pattern was observed both when participants attributed properties to God (comparisons to humans: $t(98)=3.57, p<.001$; inferences from God's actions: $t(98)=10.68$, $p<.001$; appeals to God's properties: $t(98)=5.98, p<.001)$ and when they denied properties to God (comparisons to humans: $t(98)=5.98, p<.001$; inferences from God's actions: $t(98)=6.66, p<.001$ ), with one exception in the latter case (appeals to God's properties: $t(98)=0.32, p=.75$ ). These results suggest that participants found different kinds of considerations salient when reflecting on different kinds of properties: God's similarity to humans (or lack thereof) was most salient when reflecting on God's physiological properties, but God's own nature/purpose was most salient when reflecting on God's psychological properties.

\subsubsection{Relations to religiosity}

Correlations among participants' psychological attributions, physiological attributions, theological attributions, and religiosity (Fetzer scores) are displayed in the bottom half of Table 3. The higher participants' Fetzer scores were, the more properties they attributed to God, both anthropomorphic and theological. As in Study 1, the correlations displayed at the bottom of Table 3 remained virtually unchanged when controlling for participants'

Table 4

Mean proportion of comparison-based, inference-based, and ontology-based justifications provided for each type of property and for each type of judgment in Study 2

\begin{tabular}{llccr}
\hline Justification Type & Judgment & Psychological & Physiological & Difference \\
\hline Comparisons to humans & Attributed & 0.21 & 0.31 & $-0.10^{* * *}$ \\
& Denied & 0.45 & 0.64 & $-0.19^{* * *}$ \\
Inferences from God's actions & Attributed & 0.44 & 0.19 & $0.25^{* * *}$ \\
& Denied & 0.27 & 0.09 & $0.18^{* * *}$ \\
Appeals to God's properties & Attributed & 0.44 & 0.29 & $0.15^{* * *}$ \\
& Denied & 0.23 & 0.22 & 0.01 \\
\hline
\end{tabular}

Note. ${ }^{* * *} p<.001$. 
age and gender, as the zero-order correlations between age and gender and the variables listed in Table 1 were all weak $(r(97)<.15)$ and nonsignificant. Also similar to Study 1 , the correlations between anthropomorphic attributions and theological attributions remained significant after controlling for religiosity (psychological attributions: $r$ $(97)=.39, p<.001$; physiological attributions: $r(97)=.41, p<.001)$, indicating that theological conceptions of God were seen as consistent with anthropomorphic conceptions regardless of the strength of participants' religious beliefs.

\subsection{Discussion}

Study 2 replicated two key findings of Study 1: (a) participants attributed more psychological properties to God than physiological properties, and (b) the frequency of those attributions was positively correlated with participants' religiosity. Study 2 extended those findings by assessing the relative ease with which psychological and physiological attributions were made. Compared to physiological attributions, psychological attributions were made more quickly, more confidently, and more consistently. In fact, when participants made the opposite (less common) judgment of denying psychological properties to God, they made those judgments more slowly, less confidently, and less consistently than when they denied physiological properties to God. These differences are not predicted by a "minimally counterintuitive person" view of how we anthropomorphize God, nor are they predicted by an "implicit person" view. They are, however, predicted by a "bodiless agent" view.

Also in support of the "bodiless agent" view, we found consistent dissociations between psychological and physiological dimensions of anthropomorphism in how participants justified their property judgments. While most participants justified their physiological judgments in terms of an explicit comparison to human physiology, they justified their psychological judgments in terms of their understanding of God, appealing either to God's unique ontology or to God's purported actions. This difference suggests that participants' judgments for the two types of properties were guided by qualitatively different kinds of considerations and not, it would seem, a unitary metric of God's relation to humans (e.g., a unitary "person" ontology).

\section{Study 3}

A major limitation of Studies 1 and 2 is that the participants in these studies were predominantly Christian, recruited from predominantly Christian populations. In Study 3, we explored whether our results were specific to a Christian conception of God or pertained to other religions as well-in particular, Hinduism. Our reason for targeting Hinduism was that it is a religion in which anthropomorphism is embraced, both in speech and in illustration, as a means of understanding the divine (Eck, 1998). Hindu deities are even frequently depicted as having bodies, which raises the possibility that Hindu individuals might not privilege psychological properties over physiological properties in the same 
way that Christian individuals have been shown to do. If, however, Hindu individuals do privilege psychological properties over physiological properties, then this finding would provide even stronger support for the "bodiless agent" view of how we anthropomorphize God, as the cultural input available to Hindu individuals is arguably more consistent with a "minimally counterintuitive person" conception of God than with a "bodiless agent" conception.

\subsection{Method}

\subsubsection{Participants}

The participants in Study 3 were 136 Indian adults. Thirteen additional adults took the survey but did not complete all measures and were thus excluded from the final dataset. They were recruited through Amazon Mechanical Turk and were compensated monetarily for their participation. The majority of participants (75.0\%) identified as Hindu; the rest identified as Christian (16.2\%), Muslim (4.4\%), Jain (1.5\%), Buddhist (0.7\%), Jewish $(0.7 \%)$, or something else $(1.5 \%)$. The participants in Study 3 differed from those in previous studies not only in religious affiliation but also in age, gender, and religiosity. Participants in Study 3 were, on average, 33.2-years-old, compared to 27.7 in Study 1 ( $t$ $(1659)=6.89, p<.001)$ and 19.8 in Study $2(t(233)=13.31, p<.001)$. Participants in Study 3 were $64 \%$ male, compared to $26 \%$ in Study $1\left(\chi^{2}(1,1661)=81.68, p<.001\right)$ and $29 \%$ in Study $2\left(\chi^{2}(1,235)=25.29, p<.001\right)$. And participants in Study 3 scored, on average, 4.0 on the Fetzer scale, compared to 2.6 in Study $2(t(1659)=15.55$, $p<.001)$ and 2.7 in Study $3(t(233)=12.88, p<.001)$. The added variation in age, gender, and religiosity proved useful in exploring the effects of such variables on property attributions across cultures, as noted below.

\subsubsection{Procedure}

Study 3 was conducted similarly to Study 2: Participants completed a block of property judgments under speeded conditions, followed by a second block under unspeeded conditions, followed by the Fetzer scale. Study 3 was not identical to Study 2, however; it differed in four respects. First, the tasks were administered as an online survey (in Qualtrics) rather than as a laboratory-based survey (in MediaLab). Second, we amended the instructions to include the following caveat: "If you believe in the existence of more than one god, please base your responses on the god that is most personally important to you." This caveat ensured that any participant who subscribed to a polytheistic version of Hinduism could still complete the task in much the same way that participants who subscribed to a monotheistic religion could. Third, participants were not asked to make judgments about the theological properties included in Studies 1 and 2, as those properties pertained mainly to Christian theology and were inappropriate for the sample at hand. Fourth, participants were not asked to justify their property judgments in the unspeeded trial so as to keep the length of the survey to a minimum, thereby reducing attrition. 


\subsection{Results}

\subsubsection{Property attributions}

As expected, participants attributed a higher proportion of psychological properties to God $(M=0.78, S D=0.19)$ than physiological properties $(M=0.60, S D=0.22)$, and this difference was statistically robust $(t(135)=12.56, p<.001)$. Similar to previous studies, psychological properties were attributed at a rate significantly above chance ( $t$ $(135)=17.57, p<.001)$. However, different from previous studies, physiological properties were also attributed at a rate significantly above chance $(t(135)=5.00, p<.001)$. These effects are explored in more detail in the cross-cultural comparison described below.

\subsubsection{Response times}

Mean response times for participants' property judgments are displayed in Fig. 7 as a function of property type (psychological vs. physiological) and judgment type (attributed vs. denied). As can be seen from this figure, participants were fastest when attributing psychological properties to God and next fastest when denying physiological properties to God. These data were analyzed with a repeated-measures ANOvA in which both property type and judgment type were treated as a within-participants variable. This analysis revealed no effect of property type $\left(F(1,135)=0.50, p=.48\right.$, partial $\left.\eta^{2}<.01\right)$, but a significant effect of judgment type $\left(F(1,135)=12.09, p<.01\right.$, partial $\left.\eta^{2}=.08\right)$, as participants were slightly faster when attributing properties $(M=2.5 \mathrm{~s}, S D=0.9)$ than when denying properties $(M=2.6 \mathrm{~s}, S D=1.1)$. It also revealed a significant interaction between property type and judgment type $\left(F(1,135)=40.00, p<.001\right.$, partial $\left.\eta^{2}=.23\right)$,

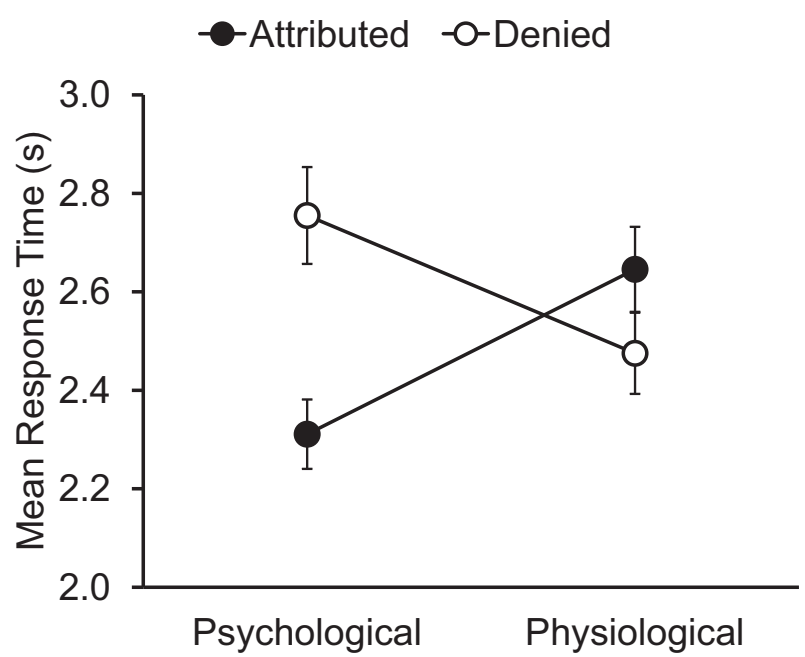

Fig. 7. Mean response times (in seconds) for property judgments in Study 3, analyzed by property type and judgment type. Error bars represent $S E$. 
consistent with Study 2. Thus, despite baseline differences in the attribution of physiological properties to God (relative to Studies 1 and 2), participants in Study 3 still attributed those properties more slowly than they attributed psychological properties, preferring instead to deny them.

\subsubsection{Confidence ratings}

Mean confidence ratings are displayed in Fig. 8. Similar to response times, confidence ratings also varied as a function of the interaction between property type (psychological vs. physiological) and judgment type (attributed vs. denied). Participants were most confident in their judgments when attributing psychological properties to God and next most confident when denying physiological properties to God. A repeated-measures ANOva confirmed that the interaction between property type and judgment type was significant $(F(1$, $135)=22.78, p<.001$, partial $\left.\eta^{2}=.14\right)$. It also revealed a significant effect of judgment type $\left(F(1,135)=11.96, p<.01\right.$, partial $\left.\eta^{2}=.08\right)$, as participants were slightly more confident in their judgments when attributing properties $(M=4.2, S D=0.7)$ than when denying properties $(M=4.1, S D=0.8)$, but no effect of property type $(F(1,135)=0.03$, $p=.87$, partial $\left.\eta^{2}<.01\right)$.

\subsubsection{Inter-trial consistency}

The consistency of participants' judgments is displayed in Fig. 9 as the mean proportion of judgments for each type of property (psychological vs. physiological) and each type of judgment (attributed vs. denied) that remained constant across trials (speeded vs. unspeeded). These data were submitted to a repeated-measures ANOva of the same type as those described above. This analysis revealed significant effects of property type $(F(1$, $135)=14.12, p<.001$, partial $\left.\eta^{2}=.10\right)$ and judgment type $(F(1,135)=40.83$,

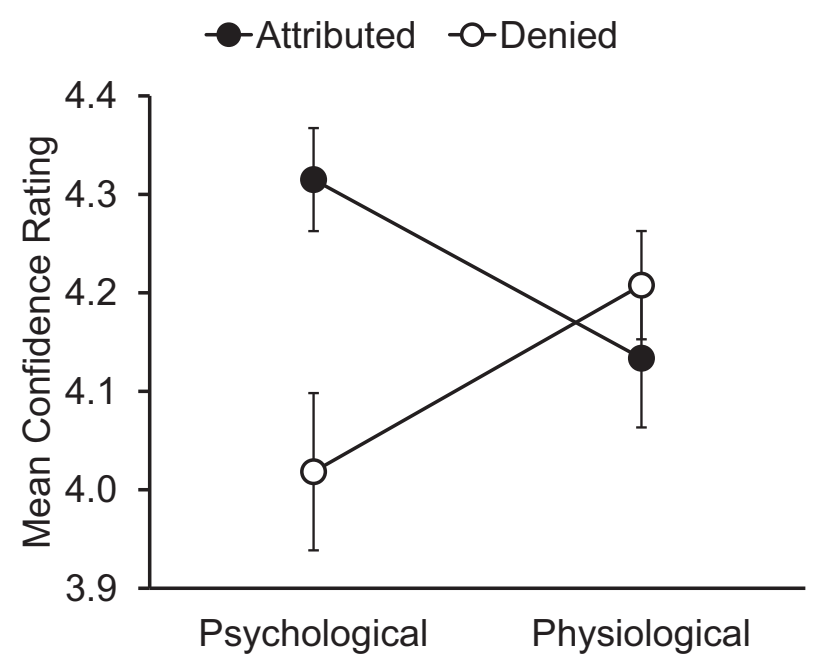

Fig. 8. Mean confidence ratings (out of five) for property judgments in Study 3, analyzed by property type and judgment type. Error bars represent $S E$. 


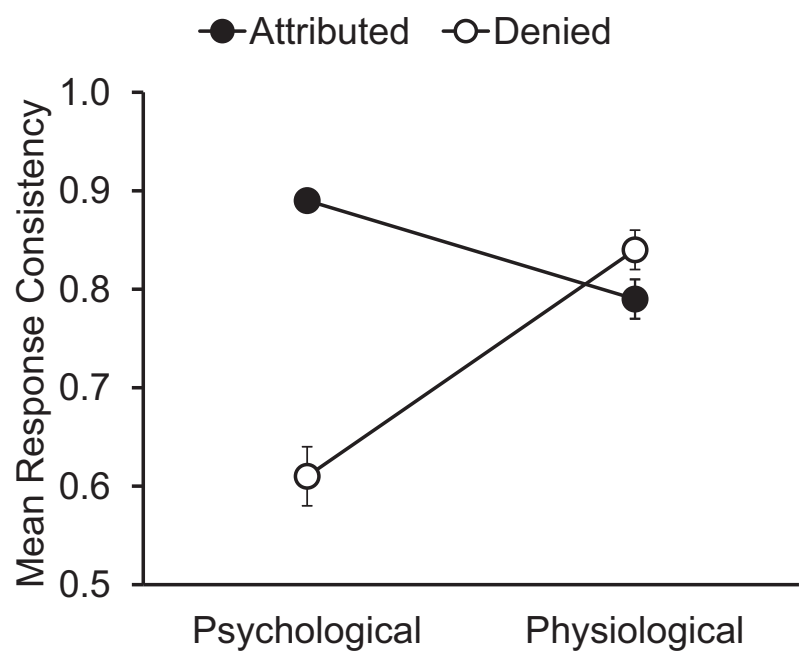

Fig. 9. Mean proportion of consistent responses across trials for property judgments in Study 3, analyzed by property type and judgment type. Error bars represent $S E$.

$p<.001$, partial $\left.\eta^{2}=.23\right)$, as participants were more consistent in their physiological judgments $(M=0.81, S D=0.22)$ than their psychological judgments $(M=0.75$, $S D=0.32)$, and more consistent in their property attributions $(M=0.84, S D=0.21)$ than in their property denials $(M=0.72, S D=0.32)$. Nevertheless, these effects were qualified by a significant interaction between property type and judgment type $(F(1,135)=43.81$, $p<.001$, partial $\eta^{2}=.25$ ). As can be seen from Fig. 9, participants were more consistent in their attribution of psychological properties than in their attribution of physiological properties, but they were more consistent in their denial of physiological properties than in their denial of psychological properties.

It should be noted that, similar to Study 2, the frequency of anthropomorphic attributions was virtually the same between speeded and under unspeeded conditions. Under speeded conditions, participants attributed an average of $78 \%$ of the psychological properties and $60 \%$ of the physiological properties; under unspeeded conditions, they attributed an average of $79 \%$ of the psychological properties and $58 \%$ of the physiological properties. Neither difference was significant (psychological properties: $t(135)=0.47, p=0.64$; physiological properties: $t(135)=1.19, p=0.24)$.

\subsubsection{Relations to religiosity}

Participants' Fetzer scores were correlated with the frequency of their psychological attributions $(r(134)=.23, p<.01)$ but were not correlated with the frequency of their physiological attributions $(r(134)=.12, p=.18)$. This lack of correlation is likely due to a lack of variation in Fetzer scores, which were uniformly high. Only $1 \%$ of participants in Study 3 scored between 1 and 2 on the Fetzer scale, and only $2 \%$ scored between 2 and 3, compared to $32 \%$ and $28 \%$ in Study 1, respectively, and $25 \%$ and $39 \%$ in Study 2, respectively. 
One additional question related to religiosity is whether the effects described above were driven by all participants or by mainly the non-Hindu participants. To address this question, we limited our dataset to participants who self-identified as Hindu $(n=102)$ and re-ran our repeated-measures ANOVAs testing the effects of property type and judgment type on (a) response times, (b) confidence ratings, and (b) inter-trial consistency. In all three analyses, the interaction between property type and judgment type remained significant (response times: $F(1,101)=32.71, p<.001$, partial $\eta^{2}=.25$; confidence ratings: $F(1,101)=15.75, p<.001$, partial $\eta^{2}=.14$; inter-trial consistency: $F(1$, $135)=26.98, p<.001$, partial $\eta^{2}=.21$ ), and the effect sizes remained comparable as well.

\subsubsection{Comparisons across studies}

Having measured the attribution of anthropomorphic properties to God across three cultural contexts-Finland, the United States, and India-we pooled those attributions and analyzed them for effects of culture. That is, we regressed the frequency of participants' anthropomorphic attributions against a dummy variable in which " 1 " stood for Finland, "2" stood for the United States, and "3" stood for India. Psychological attributions and physiological attributions were each analyzed in separate regression models. In the first step of the model, we entered three potential covariates: age, gender (coded " 1 " for male, "2" for female), and religiosity (Fetzer score). In the second step, we entered our culture variable. The results of these analyses are displayed in Table 5.

In both regressions, age and gender were small, but significant, predictors of participants' property attributions; younger participants attributed more properties to God than did older participants, and female participants attributed more properties to God than did

Table 5

Hierarchical regression analyses of participants' psychological and physiological attributions across Studies 1, 2 , and 3

\begin{tabular}{|c|c|c|c|c|c|c|}
\hline Attributions & Model & Factor & Beta & $t$ value & $R^{2}$ & $F$ Change \\
\hline \multirow[t]{7}{*}{ Psychological } & \multirow[t]{3}{*}{1} & Age & -0.14 & $7.40 * * *$ & \multirow[t]{3}{*}{.42} & \multirow[t]{3}{*}{$424.00 * * *$} \\
\hline & & Gender & 0.05 & $2.76 * *$ & & \\
\hline & & Religiosity & 0.65 & $35.14 * * *$ & & \\
\hline & \multirow[t]{4}{*}{2} & Age & -0.14 & $7.44 * * *$ & \multirow[t]{4}{*}{.42} & \multirow[t]{4}{*}{1.97} \\
\hline & & Gender & 0.06 & $3.01 * *$ & & \\
\hline & & Religiosity & 0.64 & $32.57 * * *$ & & \\
\hline & & Culture & 0.03 & 1.40 & & \\
\hline \multirow[t]{7}{*}{ Physiological } & \multirow[t]{3}{*}{1} & Age & -0.07 & $3.46 * * *$ & \multirow[t]{3}{*}{.28} & \multirow[t]{3}{*}{$219.97 * * *$} \\
\hline & & Gender & 0.09 & $4.50 * * *$ & & \\
\hline & & Religiosity & 0.53 & $25.52 * * *$ & & \\
\hline & \multirow[t]{4}{*}{2} & Age & -0.08 & $4.00 * * *$ & \multirow[t]{4}{*}{.35} & \multirow[t]{4}{*}{$192.45^{* * *}$} \\
\hline & & Gender & 0.03 & 1.40 & & \\
\hline & & Religiosity & 0.43 & $20.55 * * *$ & & \\
\hline & & Culture & 0.29 & $13.87 * * *$ & & \\
\hline
\end{tabular}

Note. ${ }^{* * p}<.01, * * * p<.001$. 
male participants. Religiosity was also a significant predictor of property attributions; the higher a participant's Fetzer score, the more properties he/she attributed to God. Altogether, these three variables - age, gender, and religiosity-explained $42 \%$ of the variance in participants' psychological attributions and $28 \%$ of the variance in participants' physiological attributions, with the lion's share explained by religiosity alone. Adding culture to the regression model did not increase the amount of variance explained in psychological attributions $(F$-change $(1,1735)=1.97, p=.16)$, but it did increase the amount of variance explained in physiological attributions $(F$-change $(1,1735)=192.45, p<.001)$, though the increase was small $(7 \%)$.

These results provide further confirmation of the "bodiless agent" view of how we anthropomorphize God. Participants in all three cultures attributed psychological properties to God at equal frequency (after controlling for baseline differences in age, gender, and religiosity), implying that they construed God as possessing a mind regardless of differences in cultural background. What did vary across cultures, however, was the extent to which participants construed God as possessing a body, with Finnish participants attributing the lowest proportion of physiological properties to God $(M=0.23$, adjusted for age, gender, and religiosity), followed by American participants $(M=0.34)$, followed by Indian participants $(M=0.48)$. Still, participants in all cultures attributed at least $18 \%$ more psychological properties to God than physiological properties, and the attribution of psychological properties proved cognitively easier than the attribution of physiological properties even among those who attributed the most physiological properties to God (i.e., the Indian participants).

\subsection{Discussion}

Study 3 replicated several key findings from Study 2 in a very different population (a predominantly Hindu population). First, participants attributed more psychological properties to God than physiological properties, and the frequency of those attributions remained the same whether participants made them under time pressure or not. Second, when participants attributed properties to God, they attributed psychological properties more quickly, more confidently, and more consistently than they attributed physiological properties. Third, when participants denied properties to God, they denied psychological properties less quickly, less confidently, and less consistently than they denied physiological properties. One major point of difference between Studies 2 and 3 was that Hindu participants attributed physiological properties to God at a rate greater than expected by chance, not less. Still, they continued to treat physiological properties differently from psychological properties along all dimensions measured, implying that their attribution of physiological properties was more cognitively demanding than their attribution of psychological properties. In other words, even though Hindu participants attributed significantly more body-dependent properties to God than did Christian participants, those attributions were still made with greater effort than were their attributions of mind-dependent properties. 


\section{General discussion}

Belief in God is central to the lives of most adults in most cultures (Brown, 1991), but much remains unknown about the conceptual foundations of this foundational belief. Previous research on the nature of God concepts has assumed that such concepts are rooted in a widespread and early developing tendency to anthropomorphize the natural world (e.g., Guthrie, 1993). The present set of studies investigated this assumption by clarifying (a) the dimensions along which God is, and is not, anthropomorphized; (b) the speed, confidence, and consistency with which those dimensions are deployed; and (c) the relation between religiosity and the anthropomorphization of God. Across three cultural contexts-Finland, the United States, and India - it was found that attributing psychological properties to God is cognitively easier than attributing physiological properties to God, as indexed by the frequency, speed, confidence, and consistency of those attributions. Likewise, denying psychological properties to God is cognitively harder than denying physiological properties to God, as indexed by the same measures. It was also found that individuals with strong religious beliefs tended to attribute more anthropomorphic (and theological) properties to God than did individuals with weaker religious beliefs, but individuals of all levels of religiosity showed the same dissociations between psychological and physiological dimensions of anthropomorphization.

These findings complement a variety of other findings in the literature on religious cognition. They complement Shtulman's (2008) finding that adults tend to attribute more psychological properties to religious beings than physical or biological properties, whether that being is God or some other religious being (e.g., Satan, angels, messiahs). They complement Bering's (2002) finding that adults make a clear distinction between psychological properties, like thinking and feeling, and biological properties, like eating and drinking, when reasoning about the continuity of life after death, with most attributing psychological properties to the dead but few attributing biological properties to the dead. And they complement Astuti and Harris's (2008) finding that, in cultures where it is commonly believed that the dead continue to exist as ancestral spirits, most people believe that psychological properties survive the transition from person to spirit but biological properties do not.

These findings also complement research on the socio-emotional role that God concepts play in the lives of religious individuals. While, on one hand, God is construed as an all-powerful creator, on the other hand, God is also construed (more mundanely) as a monitor of social relations and as an arbitrator of moral behavior. In fact, many have argued that the primary function of God concepts is to regulate social interactions and promote prosocial behavior (Gray \& Wegner, 2010; Norenzayan \& Shariff, 2008; Pyysiäinen \& Hauser, 2010). In line with this view, Shariff and Norenzayan (2007) have found that people behave more generously in anonymous economic negotiations when primed to think about God, and Purzycki et al. (2012) have found that people are quicker to attribute socially strategic knowledge to God (e.g., whether or not a person has cheated on his taxes) than to attribute nonstrategic knowledge to God (e.g., the recipe to a per- 
son's favorite cake). Even people who claim that God knows "everything" still judge God to be more knowledgeable of socially strategic information than nonstrategic information (Purzycki, 2013). Furthermore, psychological disorders that affect one's ability to read and interpret others' mental states have been shown to alter one's God concept as well, with schizotypal individuals attributing increased agency to God (Gray, Jenkins, Heberlein, \& Wegner, 2011) and autistic individuals expressing lower belief in God (Norenzayan, Gervais, \& Trzesniewski, 2012). These findings, on the whole, suggest that people are significantly more concerned with the nature of God's mind than with the nature of God's body, which was also reflected in the present studies, albeit with very different measures (property attributions).

Indeed, to the extent that our findings are consistent with a psychological conception of God, they are not consistent with a fully anthropomorphic conception of God - that is, a conception of God as a minimally counterintuitive person (Atran \& Norenzayan, 2004; Barrett, 2000; Boyer, 2001). This inconsistency is not merely semantic; the claim that God concepts are highly memorable depends on being counterintuitive, and the counterintuitiveness of God concepts depends on them God being attributed a biological and physical form against which properties like "never eats" or "is invisible" are seen as explicit violations of deep-seated commitments. One could argue that our data are, in fact, consistent with a minimally counterintuitive view of God concepts so long as their base ontology is changed from "person" to "agent," but this proposal is qualitatively different from the original proposal, as it curtails the range of properties that would be counterintuitive with respect to God's underlying ontology. Moreover, it is not the proposal that has been echoed throughout the literature on religious cognition (Atran \& Norenzayan, 2004; Grysman \& Hudson, 2012; Pennycook, Cheyne, Barr, Koehler, \& Fugelsang, 2014; Slone, 2004), particularly the literature on minimally counterintuitive concepts (Banerjee et al., 2013; Boyer \& Ramble, 2001; Johnson et al., 2010). Even when scholars have not explicitly likened God to a minimally counterintuitive person, many have done so implicitly by citing violations of folk biology and folk physics as prime contributors to God's memorability.

More important, God concepts of the form "person + counterintuitive properties" have been empirically observed among children. Shtulman (2008) asked 5-year-old children whether or not God possesses a variety of psychological and physiological properties (albeit a more limited range than those included in the present study) and found that children of this age attribute both types of properties to God at equal frequency and at nearceiling levels. In other words, children do not privilege psychological properties over physiological ones in the same way that adults do-indeed, in the same way that their own parents do (also shown in Shtulman, 2008). Accordingly, the "minimally counterintuitive person" view of how we anthropomorphize God is not a strawman; person-based concepts are the foundation of more nuanced, agent-based concepts that appear to emerge later in development.

Our findings are also inconsistent with the claim that people hold two distinct God concepts: an implicit anthropomorphic concept and an explicit theological concept (Barrett \& Keil, 1996; Bulbulia, 2004; Cohen et al., 2008; Pyysiäinen, 2004; Slone, 2004; 
Subbotsky, 2005). In Studies 1 and 2, participants readily attributed to God both anthropomorphic properties and theological properties. In fact, the more religious participants were-and thus, arguably, the more familiar they were with theological descriptions of God - the more likely they were to attribute physiological properties to God, including specific, concrete properties like "has bones" or "has a height that can be measured in centimeters." Other studies have not supported the anthropomorphic-theological distinction either. Morewedge and Clear (2008), for example, found that agreement with theological God concepts was strongly and positively associated with agreement with anthropomorphic God concepts. Likewise, Shtulman (2010) found that participants who claimed to have acquired their God concepts from a religious authority or theological doctrine were more likely to anthropomorphize God than those who claimed to have acquired their concept from family members or through self reflection.

An additional point of inconsistency with the dual-concept view was the finding, from Studies 2 and 3, that participants' attributions differed only slightly between speeded and unspeeded conditions, even though placing participants under time pressure is known to encourage default, intuitive responses that are otherwise inhibited by later acquired knowledge (Bargh, 1989; Logan \& Zbrodoff, 1982; Shtulman \& Valcarcel, 2012; Wilkowski \& Robinson, 2007). In other words, if participants held an implicit concept of God that was significantly more anthropomorphic than their explicit concept - an abstract, theological concept acquired later in life - then they should have attributed substantially more human properties to God in the speeded condition than in the unspeeded condition, but they did not. The difference in property attributions between conditions was negligible across domains and across studies.

Because we collected only property judgments, it is possible that our participants may have revealed more anthropomorphic conceptions of God in more implicit tasks, such as a story-recall task. Still, the conceptions that participants did reveal tended to be highly anthropomorphic as is. Few participants held explicit conceptions of God that were so abstract as to preclude the attribution of most psychological properties $(50 \%-80 \%)$ and a nontrivial percentage of physiological properties (20\%-50\%). Moreover, the fact that most participants saw no contradiction in attributing to God both concrete, anthropomorphic properties and abstract, theological properties implies that there is no theoretical reason to posit separate explicit and implicit concepts.

And there may be no empirical reason either. Previous studies (e.g., Barrett \& Keil, 1996) have shown that people explicitly endorse theological conceptions of God and implicitly endorse anthropomorphic conceptions of God, but they have not shown that people explicitly reject anthropomorphic conceptions - that is, that they explicitly reject the same anthropomorphic properties that they implicitly endorse. Without those data, it is not clear why God concepts need to be split in two. Indeed, participants' propensity to anthropomorphize God in implicit tasks may well reflect a propensity to anthropomorphize God in explicit tasks as well. The logical inconsistency between (a) claiming that God is omniscient and (b) imposing limitations on God's knowledge in a story-recall task may not be obvious to most people even at an explicit level. Barrett and Keil (1996) assumed that people could only make such a mistake if they held representationally 
distinct God concepts activated in cognitively distinct tasks, but our data suggest that many people are psychologically content to attribute logically incompatible properties. The coherence of God concepts across properties and across tasks clearly merits further investigation.

On the whole, participants attributed significantly more psychological properties to God than physiological properties, but there were exceptions within both domains. Physiological properties that participants were inclined to attribute to God (e.g., "exerts force," "has a stable existence," "can move a material object") were those that infants appear to attribute to physical objects (Baillargeon, 2004; Spelke, 1990). Physiological properties that participants were not inclined to attribute to God, on the other hand, were those that children come to understand much later in development, like "has bones," "has lungs," and "can reproduce" (Hatano \& Inagaki, 1994; Slaughter \& Lyons, 2003). Similarly, psychological properties that participants were inclined to attribute to God (e.g., "can see," "can make plans," "can be happy") were those that children learn early and easily, whereas psychological properties that participants were not inclined to attribute to God (e.g., "can taste," "can smell," "can sense coldness") were properties that children understand much later in development and which are typically not characterized as foundational or core knowledge about human beings (Carey, 1985; Leslie, 1994; Wellman \& Gelman, 1992).

Analyzed in this way, participants' attribution patterns appear to be symptomatic of what Lindeman and Aarnio (2007) have termed "core knowledge confusions," or instances in which early- and easily-learned properties of one foundational domain are applied (inappropriately) to the entities within another. Examples include misapplying properties of living organisms to lifeless objects (e.g., attributing the ability to weep to statues), misapplying mental properties to physical, inanimate phenomena (e.g., attributing intentionality to random events), and misapplying physical properties to mental phenomena (e.g., attributing physical causality to thought). Lindeman and colleagues have found that susceptibility to core knowledge confusions is strongly related to religious and other paranormal beliefs (Lindeman \& Aarnio, 2007; Lindeman, Svedholm-Häkkinen, \& Lipsanen, 2015; Svedholm \& Lindeman, 2013). The present work extends this analysis to God concepts, as God concepts could be characterized as core knowledge confusions between physical, biological, and psychological phenomena-that is, as the misapplication of select biological properties, like "lives," and select physical properties, like "has an independent existence," to the human mind.

In sum, the findings presented here suggest that anthropomorphism (gr. anthropo = human) may not be the best way to characterize people's God concepts, if anthropomorphism is interpreted as the projection of any and all human properties to nonhuman entities. Instead, God concepts may be better characterized as agentive or even animistic (lat. anima = soul, spirit, breath). Other scholars interested in the origin and nature of God concepts have characterized such concepts as "anthropomorphic," but the nature of that anthropomorphism has remained largely unspecified. Here, we have shown just what kind of anthropomorphic entity God is assumed to be: a living, independentlyexisting mind - that is, a mind that can live without possessing the biological properties 
characteristic of ordinary living things and that can exert force without possessing the material properties characteristic of ordinary physical entities. Whether or not this analysis is correct, we maintain that future research should focus not just on the development of God's extraordinary properties (e.g., omniscience, immortality) but also on the development of God's "ordinary" properties, like seeing, hearing, wanting, and knowing. It is these properties, after all, that have inspired anthropomorphic explanations of religion from Xenophanes' time to the present.

\section{Acknowledgment}

We thank Paul Lindroos, Rourke Healey, Isabel Hubbard, Amanda Schlitt, and Andrea Villalobos for their assistance with data collection and data analysis.

\section{References}

Armstrong, K. (1994). A history of God: The 4000-year quest of Judaism, Christianity, and Islam. New York: Ballantine Books.

Astuti, R., \& Harris, P. L. (2008). Understanding mortality and the life of the ancestors in rural Madagascar. Cognitive Science, 32, 713-740.

Atran, S., \& Norenzayan, A. (2004). Religion's evolutionary landscape: Counterintuition, commitment, compassion, communion. Behavioral and Brain Sciences, 27, 713-730.

Baillargeon, R. (2004). Infants' physical world. Current Directions in Psychological Science, 13, 89-94.

Banerjee, K., Haque, O. S., \& Spelke, E. S. (2013). Melting lizards and crying mailboxes: Children's preferential recall of minimally counterintuitive concepts. Cognitive Science, 37, 1251-1289.

Bargh, J. A. (1989). Conditional automaticity: Varieties of automatic influence in social perception and cognition. In J. S. Uleman \& J. A. Bargh (Eds.), Unintended thought (pp. 3-51). New York: Guilford Press.

Barrett, J. L. (2000). Exploring the natural foundations of religion. Trends in Cognitive Sciences, 4, 29-34.

Barrett, J. L., \& Keil, F. C. (1996). Conceptualizing a nonnatural entity: Anthropomorphism in God concepts. Cognitive Psychology, 31, 219-247.

Barrett, J. L., Richert, R. A., \& Driesenga, A. (2001). God's beliefs versus mother's: The development of nonhuman agent concepts. Child Development, 72, 50-65.

Bering, J. M. (2002). Intuitive conceptions of dead agents' minds: The natural foundations of afterlife beliefs as phenomenological boundary. Journal of Cognition and Culture, 2, 263-308.

Bloom, P., \& Veres, C. (1999). The perceived intentionality of groups. Cognition, 71, B1-B9.

Boyer, P. (2001). Religion explained: The evolutionary origins of religious thought. New York: Basic Books.

Boyer, P., \& Ramble, C. (2001). Cognitive templates for religious concepts: Cross-cultural evidence for recall of counter-intuitive representations. Cognitive Science, 25, 535-564.

Brown, D. E. (1991). Human universals. New York: McGraw-Hill.

Bulbulia, J. (2004). The cognitive and evolutionary psychology of religion. Biology and Philosophy, 19, 655686.

Carey, S. (1985). Conceptual change in childhood. Cambridge, MA: MIT Press.

Cassiba, R., Granqvist, P., Costantini, A., \& Gatto, S. (2008). Attachment and God representations among lay Catholics, priests, and religious: A matched comparison study based on the adult attachment interview. Developmental Psychology, 44, 1753-1763. 
Cohen, A. B., Shariff, A. F., \& Hill, P. C. (2008). The accessibility of religious beliefs. Journal of Research in Personality, 42, 1408-1417.

De Roos, S. A., Miedema, S., \& Iedema, J. (2001). Attachment, working models of self and others, and God concept in kingergarten. Journal for the Scientific Study of Religion, 40, 607-618.

Dickie, J. R., Eshleman, A. K., Merasco, D. M., Shepard, A., Wilt, M. V., \& Johnson, M. (1997). Parentchild relationships and children's images of God. Journal for the Scientific Study of Religion, 36, 25-43.

Eck, D. L. (1998). Darśan: Seeing the divine image in India. New York: Columbia University Press.

Epley, N., Akalis, S., Waytz, A., \& Cacioppo, J. T. (2008). Creating social connection through inferential reproduction: Loneliness and perceived agency in gadgets, gods, and greyhounds. Psychological Science, 19, 114-120.

Epley, N., Waytz, A., \& Cacioppo, J. T. (2007). On seeing human: A three-factor theory of anthropomorphism. Psychological Review, 114, 864-886.

Gergely, G., Nadasdy, Z., Csibra, G., \& Biro, S. (1995). Taking the intentional stance at 12 months of age. Cognition, 56, 165-193.

Giménez-Dasí, M., Guerrero, S., \& Harris, P. L. (2005). Intimations of immortality and omniscience in early childhood. European Journal of Developmental Psychology, 2, 285-297.

Gray, K., \& Wegner, D. M. (2010). Blaming god for our pain: Human suffering and the divine mind. Personality and Social Psychology Review, 14, 7-16.

Gray, K., Jenkins, A. C., Heberlein, A. S., \& Wegner, D. M. (2011). Distortions of mind perception in psychopathology. Proceedings of the National Academy of Sciences, 108, 477-479.

Grysman, A., \& Hudson, J. A. (2012). Agency detection in God concepts: Essential, situational, and individual factors. Journal of Cognition and Culture, 12, 1-2.

Guthrie, S. (1993). Faces in the cloud. Oxford, UK: Oxford University Press.

Haslam, N., Kashima, Y., Loughnan, S., Shi, J., \& Suitner, C. (2008). Subhuman, inhuman, and superhuman: Contrasting humans with nonhumans in three cultures. Social Cognition, 26, 248-258.

Hatano, G., \& Inagaki, K. (1994). Young children's naïve theory of biology. Cognition, 50, 171-188.

Heider, F., \& Simmel, M. (1944). An experimental study of apparent behavior. American Journal of Psychology, 57, 243-259.

Hume, D. (1757/2009). The natural history of religion. Oxford, UK: Oxford University Press.

Janoff-Bulman, R. (1989). Assumptive worlds and the stress of traumatic events: Applications of the schema construct. Social Cognition, 7, 113-136.

Johnson, C. V. M., Kelly, S. W., \& Bishop, P. (2010). Measuring the mnemonic advantage of counterintuitive and counter-schematic concepts. Journal of Cognition and Culture, 10, 109-121.

Johnson, S. C., Slaughter, V., \& Carey, S. (1998). Whose gaze will infants follow? Features that elicit gazefollowing in 12-month-olds. Developmental Science, 1, 233-238.

Kelemen, D. (2004). Are children "Intuitive theists"? Psychological Science, 15, 295-301.

Kirkpatrick, L. A. (2005). Attachment, evolution, and the psychology of religion. New York: Guilford.

Knight, N., Sousa, P., Barrett, J. L., \& Atran, S. (2004). Children's attributions of beliefs to humans and God: Cross-cultural evidence. Cognitive Science, 28, 117-126.

Lane, J. D., Wellman, H. M., \& Evans, E. M. (2010). Children's understanding of ordinary and extraordinary minds. Child Development, 81, 1475-1489.

Lane, J. D., Wellman, H. M., \& Evans, E. M. (2014). Approaching an understanding of omniscience from the preschool years to early adulthood. Developmental Psychology, 50, 2380-2392.

Legare, C. H., Lane, J. D., \& Evans, E. M. (2013). Anthropomorphizing science: How does it affect the development of evolutionary concepts. Merrill-Palmer Quarterly, 59, 168-197.

Lesher, J. H. (2001). Xenophanes of Colophon: Fragments. Toronto: University of Toronto Press.

Leslie, A. M. (1994). ToMM, ToBY, and Agency: Core architecture and domain specificity. In L. A. Hirschfeld \& S. A. Gelman (Eds.), Mapping the mind: Domain specificity in cognition and culture (pp. 119-148). Cambridge, UK: Cambridge University Press. 
Lindeman, M., \& Aarnio, K. (2007). Superstitious, magical, and paranormal beliefs: An integrative model. Journal of Research in Personality, 41, 731-744.

Lindeman, M., Pyysiäinen, I., \& Saariluoma, P. (2002). Representing God. Papers on Social. Representations, 11, 1-13.

Lindeman, M., Svedholm-Häkkinen, A. M., \& Lipsanen, J. (2015). Ontological confusions but not mentalizing abilities predict religious belief, paranormal belief, and belief in supernatural purpose. Cognition, 134, 63-76.

Logan, G. D., \& Zbrodoff, N. J. (1982). Constraints on strategy construction in a speeded discrimination task. Journal of Experimental Psychology: Human Perception and Performance, 8, 502-520.

Makris, N., \& Pnevmatikos, D. (2007). Children's understanding of human and supernatural minds. Cognitive Development, 22, 365-375.

Morewedge, C. K., \& Clear, M. E. (2008). Anthropomorphic god concepts engender moral judgment. Social Cognition, 26, 182-189.

Nakhleh, M. B., Samarapungavan, A., \& Saglam, Y. (2005). Middle school students' beliefs about matter. Journal of Research in Science Teaching, 42, 581-612.

Nass, C., \& Moon, Y. (2000). Machines and mindlessness: Social responses to computers. Journal of Social Issues, 56, 81-103.

Neff, J. A. (2006). Exploring the dimensionality of "religiosity" and "spirituality" in the Fetzer multidimensional measure. Journal for the Scientific Study of Religion, 45, 449-459.

Norenzayan, A., Atran, S., Faulkner, J., \& Schaller, M. (2006). Memory and mystery: The cultural selection of minimally counterintuitive narratives. Cognitive Science, 30, 531-553.

Norenzayan, A., Gervais, W. M., \& Trzesniewski, K. H. (2012). Mentalizing deficits constrain belief in a personal God. PLoS ONE, 7, e36880.

Norenzayan, A., \& Shariff, A. F. (2008). The origin and evolution of religious prosociality. Science, 322, 5862.

Pennycook, G., Cheyne, J. A., Barr, N., Koehler, D. J., \& Fugelsang, J. A. (2014). Cognitive style and religiosity: The role of conflict detection. Memory \& Cognition, 42, 1-10.

Piaget, J. (1929/1951). The child's conception of the world. London, UK: Routledge \& Kegan.

Purzycki, B. G. (2013). The minds of gods: A comparative study of supernatural agency. Cognition, 129, $163-179$.

Purzycki, B. G., Finkel, D. N., Shaver, J., Wales, N., Cohen, A. B., \& Sosis, R. (2012). What does God know? Supernatural agents' access to socially strategic and non-strategic information. Cognitive Science, $36,846-869$.

Pyysiäinen, I. (2004). Intuitive and explicit in religious thought. Journal of Cognition and Culture, 4, 123150.

Pyysiäinen, I., \& Hauser, M. (2010). The origins of religion: Evolved adaptation or by-product? Trends in Cognitive Sciences, 14, 104-109.

Richert, R. A., \& Barrett, J. L. (2005). Do you see what I see? Young children's assumptions about God's perceptual abilities. The International Journal for the Psychology of Religion, 15, 283-295.

Shariff, A. F., \& Norenzayan, A. (2007). God is watching you: Priming God concepts increases prosocial behavior in an anonymous economic game. Psychological Science, 18, 803-809.

Shtulman, A. (2008). Variation in the anthropomorphization of supernatural beings and its implications for cognitive theories of religion. Journal of Experimental Psychology: Learning, Memory, and Cognition, 34, $1123-1138$.

Shtulman, A. (2010). Theories of God: Explanatory coherence in a non-scientific domain. In S. Ohlsson \& R. Catrambone, (Eds.), Proceedings of the 32nd Annual Conference of the Cognitive Science Society (pp. 1295-1300). Austin, TX: Cognitive Science Society.

Shtulman, A., \& Valcarcel, J. (2012). Scientific knowledge suppresses but does not supplant earlier intuitions. Cognition, 124, 209-215. 
Slaughter, V., \& Lyons, M. (2003). Learning about life and death in early childhood. Cognitive Psychology, $43,1-30$.

Slone, J. D. (2004). Theological incorrectness: Why religious people believe what they shouldn't. Oxford, UK: Oxford University Press.

Smith, C. L. (2007). Bootstrapping processes in the development of students' commonsense matter theories: Using analogical mappings, thought experiments, and learning to measure to promote conceptual restructuring. Cognition and Instruction, 25, 337-398.

Spelke, E. S. (1990). Principles of object perception. Cognitive Science, 14, 29-56.

Subbotsky, E. (2005). The permanence of mental objects: Testing magical thinking on perceived and imaginary realities. Developmental Psychology, 41, 301-318.

Svedholm, A. M., \& Lindeman, M. (2013). The separate roles of the reflective mind and involuntary inhibitory control in gatekeeping paranormal beliefs and the underlying intuitive confusions. British Journal of Psychology, 104, 303-319.

Tylor, E. B. (1871/1974). Primitive culture: Research into the development of mythology, philosophy, religion, art, and custom. New York: Gordon Press.

Upal, M. A., Gonce, L. O., Tweney, R. D., \& Slone, D. J. (2007). Contextualizing counterintuitiveness: How context affects comprehension and memorability of counterintuitive concepts. Cognitive Science, 31, 415439.

Waytz, A., Cacioppo, J., \& Epley, N. (2010). Who sees human? The stability and importance of individual differences in anthropomorphism. Perspectives on Psychological Science, 5, 219-232.

Wellman, H. M., \& Gelman, S. A. (1992). Cognitive development: Foundational theories of core domains. Annual Review of Psychology, 43, 337-375.

White, P. A. (1992). The anthropomorphic machine: Causal order in nature and the world view of common sense. British Journal of Psychology, 83, 61-96.

Wilkowski, B. M., \& Robinson, M. D. (2007). Keeping one's cool: Trait anger, hostile thoughts, and the recruitment of limited capacity control. Personality and Social Psychology Bulletin, 33, 1201-1213.

Willard, A. K., \& Norenzayan, A. (2013). Cognitive biases explain religious belief, paranormal belief, and belief in life's purpose. Cognition, 129, 379-391.

Woodward, A. (1998). Infants selectively encode the goal object of an actor's reach. Cognition, 69, 1-34. 